

\title{
INVESTIGATION OF LMFBR PROTOTYPE 7A HEATERS AND THE METALLURGY OF THE PLATINUM-8 WEIGHT PERCENT TUNGSTEN ALLOY
}

\author{
R. L. Ludwig
}

Metallurgical Development Department Y-12 Development Division

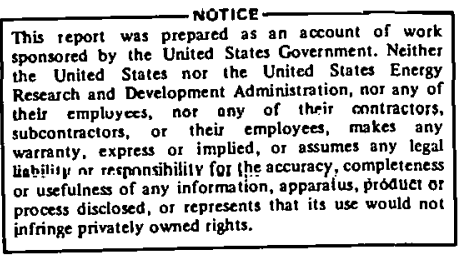

Oak Ridge Y-12 Plant

P. O. Box Y, Oak Ridge, Tennessee 37830

Prepared for the US Energy Research and Development Administration

Under US Government Contract W-7405-eng-26 


\section{DISCLAIMER}

This report was prepared as an account of work sponsored by an agency of the United States Government. Neither the United States Government nor any agency Thereof, nor any of their employees, makes any warranty, express or implied, or assumes any legal liability or responsibility for the accuracy, completeness, or usefulness of any information, apparatus, product, or process disclosed, or represents that its use would not infringe privately owned rights. Reference herein to any specific commercial product, process, or service by trade name, trademark, manufacturer, or otherwise does not necessarily constitute or imply its endorsement, recommendation, or favoring by the United States Government or any agency thereof. The views and opinions of authors expressed herein do not necessarily state or reflect those of the United States Government or any agency thereof. 


\section{DISCLAIMER}

Portions of this document may be illegible in electronic image products. Images are produced from the best available original document. 
Reference to a company or product name does not imply approval or recommendation of the product by Union Carbide Corporation or the U.S. Energy Research and Development Administration to the exclusion of others that may meet specifications.

Printed in the United States of America. Available from National Technical Information Service

U.S. Department of Commerce

5285 Port Royal Road, Springfield, Virginia 22161

Price: Printed Copy $\$ 4.00$; Microfiche $\$ 2.25$

This report was prepared as an account of work sponsored by the United States Government. Neither the United States nor the Energy Research and Development Administration/United States Nuclear Regulatory Commission, nor any of their employees, nor any of their contractors, subcontractors, or their employees, makes any warranty, express or implied, or assumes any legal liability or responsibility for the accuracy, completeness or usefulness of any information, apparatus, product or process disclosed, or represents that its use would not infringe privately owned rights. 


\begin{abstract}
A Liquid Metal Fast Breeder Reactor 7A prototype heater failure was analyżed. The failure was due to melting of the platinum- 8 weight percent tungsten alloy (Pt-8 W) alloy winding caused by a loss of contact with the inside boron nitride insulation. An attempt to simulate a failure revealed that elemental boron forms a low-melting mixture with Pt- $8 \mathrm{~W}$, but a means by which boron might be present in an actual heater. was not determined.

A time/temperature/grain size study of various Pt-8 $\mathrm{W}$ alloy samples resulted in behavior which would be expected from a single-phase, solid-solution alloy. The results of the study were useful in estimating the temperatures reached at various locations along the length of two failed $7 \mathrm{~A}$ prototype heaters.
\end{abstract}




\section{CONTENTS}

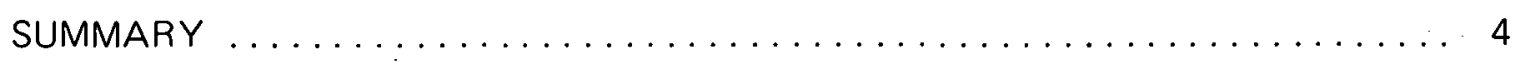

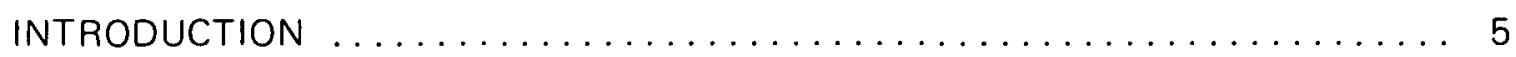

INVESTIGATION OF THE PROTOTYPE TA HEATERS $\ldots \ldots \ldots \ldots \ldots \ldots \ldots$

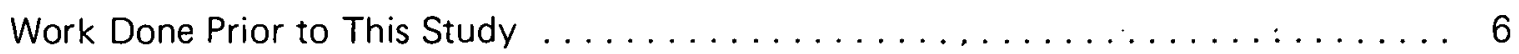

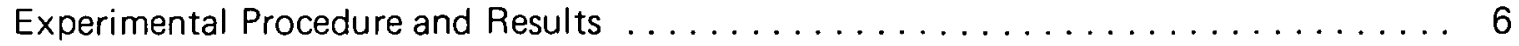

Investigation of the Second 7A Prototype Heater Failure . . . . . . . . . 7

Time/Temperature/Grain Size/Hardness Study . . . . . . . . . . . 8

Examination of the Platinum-8 Tungsten Alloy Winding from Two

Failed 7A Prototype Heaters ............. 11

Chemical Homogeneity of As-Received 6A and 7A Platinum-8

Tungsten Alloy Ribbon and Prototype 7A

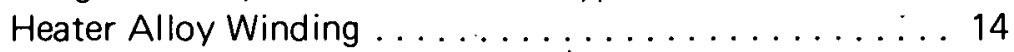

Boron Nitride Density in the Annular Area of the Heaters . . . . . . . . . . . 15

Simulation of Melting Platinum-8 Tungsten Alloy Ribbon Used in the

Heaters and Analysis of the Molten. Failure Areas .... 16

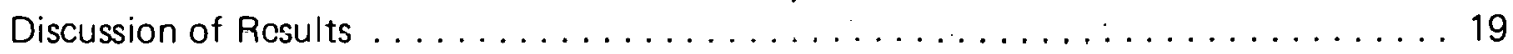

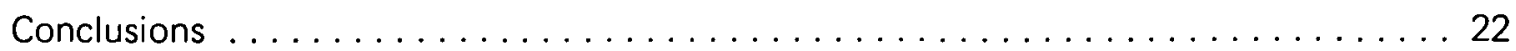

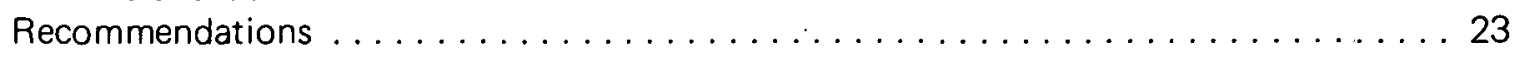

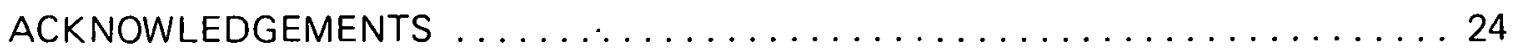

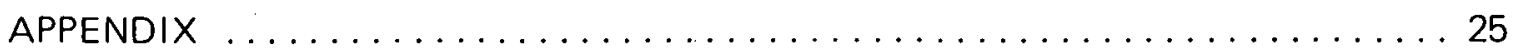

Photomicrographs of the Alloy Specimens after Various Heat Treatments . . . . . 25 


\begin{abstract}
SUMMARY
Platinum-8 weight percent tungsten alloy (Pt-8 W) was selected as the resistance element materials for an advanced group of high-heat-flux heaters for the Liquid Metal Fast Breeder Reactor (LMFBR) fuel-failure mockup (FFM) studies. For heater fabrication, an alloy ribbon is wound into a variable-pitch helix which is surrounded by boron nitride (BN) insulation within a stainless steel sheath, and the entire assembly is compacted by swaging. Failure of one 7A prototype heater by melting of the alloy element prompted an investigation; a second, similar failure resulted in the more extensive failure analysis and metallurgical study reported herè.
\end{abstract}

An investigation of the second failure revealed that melting was due to a loss of thermal contact between the winding and the inner BN, and that the molten area containcd an apparent low-melting platinum/boron eutectic.

A time/temperature/grain size study was made to characterize the behavior of the alloy and establish a standard by which to estimate the temperature reached in various locations of the failed heaters. Grain-growth results were about as would be expected from a single-phase, solid-solution alloy. Critical grain growth was observed in some specimens which had been strained slightly prior to heat treatment. Grain-size comparisons with specimens of windings from the failed heaters revealed that the temperature reached by the windings varied nonuniformly along the length, suggesting that a variable density in the BN might be affecting heat transfer. Because winding of the coils tended to introduce a critical amount of strain, the estimate of the temperature reached in a particular location of the winding was tempered by the knowledge that critical grain growth could occur such that the actual temperature reached might be overestimated.

Experiments were run to investigate the melting of the Pt- $8 \mathrm{~W}$ alloy ribbon. The possibility of incomplete alloying contributing to melting was examined by electron-beam microprobe analyses of several representative specimens. Some compositional variability was observed, but it was not sufficient to significantly effect a localized variability in the melting point. As noted earlier, boron had been determined to be present in the melted allov ribbon. Several tests were run to determine if this platinum/boron structure could be duplicated experimentally. A piece of the alloy ribbon and $B N$ were heated in contact in argon to $1600^{\circ} \mathrm{C}$ for a short time, but no reaction occurred. Reheating the two with the addition of a small quantity of boric oxide again produced no reaction. However, heating the alloy in contact with elemental boron caused melting to take place exothermally, beginning at $1385^{\circ} \mathrm{C}$. It appears, then, that melting can take place below the melting range of the alloy, but that elemental boron, possibly from the elevated-temperature decomposition of BN, must be present for it to oncuur. 


\section{INTRODUCTION}

Electrically powered heaters are used to simulate the fuel rods in the FFM Studies for the LMFBR. Nichrome $V$ and Kanthal A1 alloys have been used as the resistance elements in the heaters, but a material with a higher melting and operating temperature was required to achieve the greater heat fluxes needed for future tests. Platinum/tungsten alloy was selected for use. Tungsten imparts strength and toughness to platinum and decreases its temperature coefficient of resistivity. An alloy of $8 \mathrm{wt} \%$ tungsten was selected on the basis that greater amounts of the metal result in the alloy's being workable only with great difficulty.

The heaters are manufactured by winding the $0.30 \times 3.18 \mathrm{~mm}(0.012 \times 0.125 \mathrm{in}) \mathrm{Pt}-8 \mathrm{~W}$ ribbon into a variable-pitch spiral of $3.18 \mathrm{~mm}(0.125 \mathrm{in})$ outside diameter. Hot-pressed and machined $\mathrm{BN}$ rods are placed inside the winding, and the winding plus core is positioned inside a $6.35-\mathrm{mm}(0.250$-in)-OD Type 316 stainless steel tube. BN powder is tamped into the annular space between the tube ID and winding, and the entire assembly is swaged to a 5.84-mm (0.230-in) OD to densify the BN and bring the components into intimate contact. During preliminary tests of these heaters (designated as 7A prototypes), failures occurred because the alloy ribbon melted. A report of the investigation of one such failure has been reported to the Oak Ridge National Laboratory. After a second failure, a more thorough investigation of the Pt-8 W alloy was undertaken at the Oak Ridge Y-12 Plant, (a) both with respect to its metallurgical behavior and as a function of its environment in the heater.

- (a) Operated by the Union Carbide Corporation's Nuclear Division for the US Energy Research and Development Administration. 


\section{INVESTIGATION OF THE PROTOTYPE 7A HEATERS}

\section{WORK DONE PRIOR TO THIS STUDY}

The more pertinent findings in the investigation of the first failure were:

1. Melting of the alloy occurred at the two failure locations; and, for a distance on each side of the molten zone, grain growth took place such that the ribbon became about one grain thick and several grains wide. Intergranular cracks formed through the ribbon on both sides of each melted area a short distance away.

2. A $2.1-\mathrm{mm}(0.085-\mathrm{in})$ gap in the $B N$ core rod was located at the point at which the most severe melting took place. A smaller $[0.4-\mathrm{mm}(0.015-\mathrm{in})]$ gap was present at the second area where melting was observed.

3. In the melted areas, a second phase was present both within the grains and at the grain boundaries. An electron-beam (FB) microprobe analysis indicated that these areas were apparèntly pure platinum, free of tungsten. Boron was observed to be present in a very small amount, dispersed uniformly over the sample; however, the EB microprobe is relatively insensitive to boron.

\section{EXPERIMENTAL PROCEDURE AND RÉSULTS}

When the second 7A prototype heater failed, the following investigative procedure was initiated:

1. Investigatè the second failure.

2. Perform a time/temperature/grain size/hardness study on the following materials:

a. As-received 6A, 7A, and 8A alloy ribbon.

b. As-wound 7A ribbon.

c. As-wound and swaged 7A ribbon.

d. As-wound 8 A ribbon.

e. Ribbon from the $6 \mathrm{~A}$ and $7 \mathrm{~A}$ heaters which had been operated.

3. Analyze other areas in the two failed 7A prototype heaters and compare them with the failure areas.

4. Determine the grain size, chemistry (local), and hardness of the original alloy ribbons used in the $6 \mathrm{~A}$ and $7 \mathrm{~A}$ bundle heaters.

5. Measure the BN density in the annular area of the 7A prototype heater and a $6 \mathrm{~A}$ heater at selected locations. 
6. Attempt to simulate or reproduce the metallurgical structure observed in the melted area of the alloy ribbon in the first failed 7A prototype heater.

\section{Investigation of the Second 7A Prototype Heater Failure}

A radiograph had indicated that a defective area in the winding existed at a distance of $330 \mathrm{~mm}$ (13 in) from the ground end of the winding of the second failed 7A prototype heater. A section [32 mm (1 1/4 in) long] that contained the defect was cut from the heater, and two lengthwise cuts about 170 degrees apart were made through the sheath to expose the defective area. The BN was scraped away from the winding; and, because of softening or partial melting of the winding, the $\mathrm{BN}$ was observed to be tightly adhered to the two turns on each side of the defect. The defect was revealed to be a melted-out area in the winding, as indicated in Figure 1. The sharp edge on the outside surface of the melted winding suggests that the melting was most severe on the inner surface.

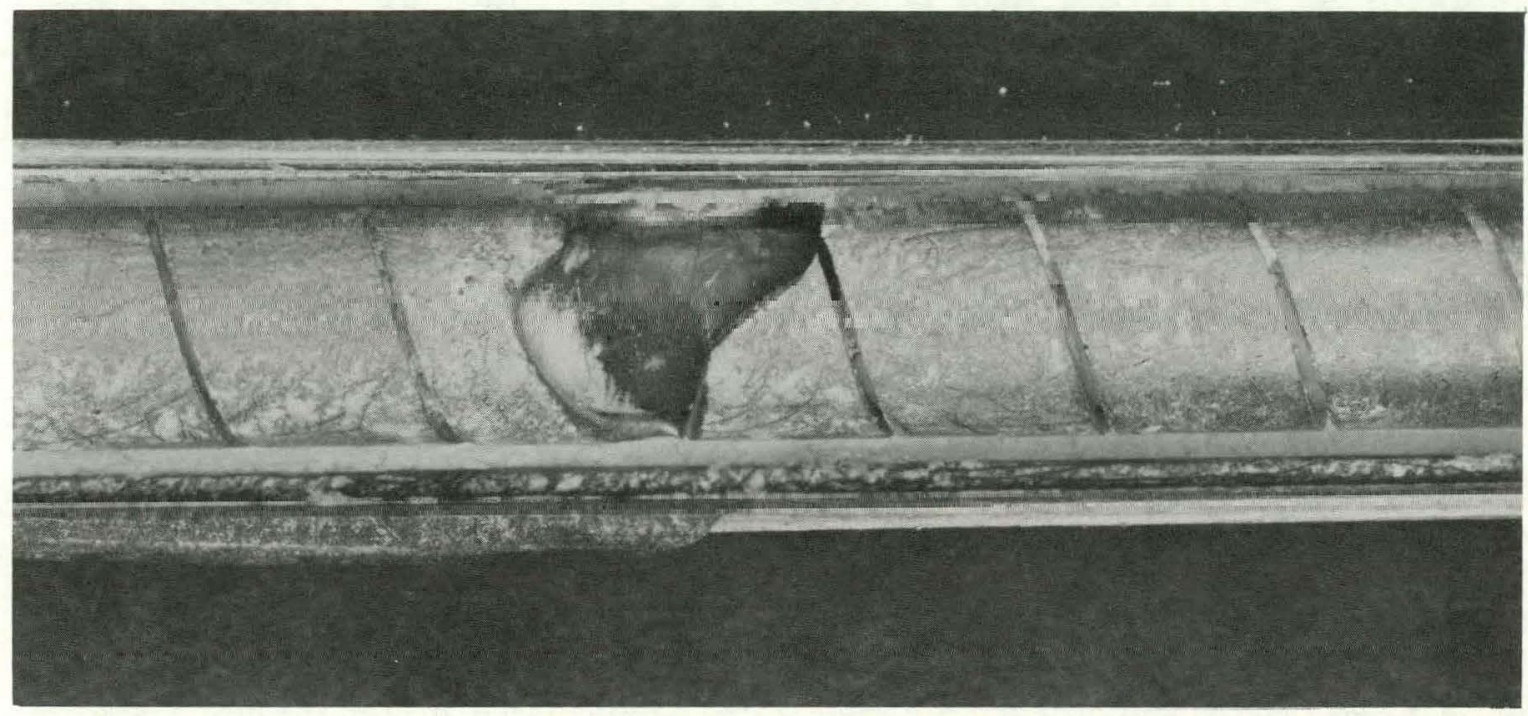

L.353C

Figure 1. MELTED PLATINUM-8 TUNGSTEN ALLOY WINDING WHICH CAUSED FAILURE OF THE $7 A$ PROTOTYPE HEATER. $(8 X)$

The BN core was blackened in the area where the alloy had melted, and there was no visible gap or separation in the core. Neither was there any indication as to the place where the molten metal had been deposited. The sheath was carefully removed, leaving the winding and outer $\mathrm{BN}$ intact, and the outer $\mathrm{BN}$ was scraped away from the area underneath the melt (Figure 2). In this way it was ascertained that none of the molten alloy had been deposited external to the winding. Since there was no break in the core, the only place into which the metal could flow would be a radial gap between the inside diameter of the winding and the BN core rod. Looking at Figure 1, the left side of the winding was metallographically mounted with its axis vertical such that the true thickness of the winding could be determined in the melted area. Figure 3 contains two cross sections from this specimen from locations separated axially by $0.5 \mathrm{~mm}(0.020 \mathrm{in})$. The alloy winding has been at or close to its melting range; but, more importantly, the fine eutectic-like structure on the inside diameter is once-molten alloy which has flowed into the radial gap between the core rod and 
winding, increasing the original $0.030-0.33-\mathrm{mm}(0.012-0.013$-in) ribbon thickness to a maximum of about $0.41 \mathrm{~mm}$ (0.016 in).

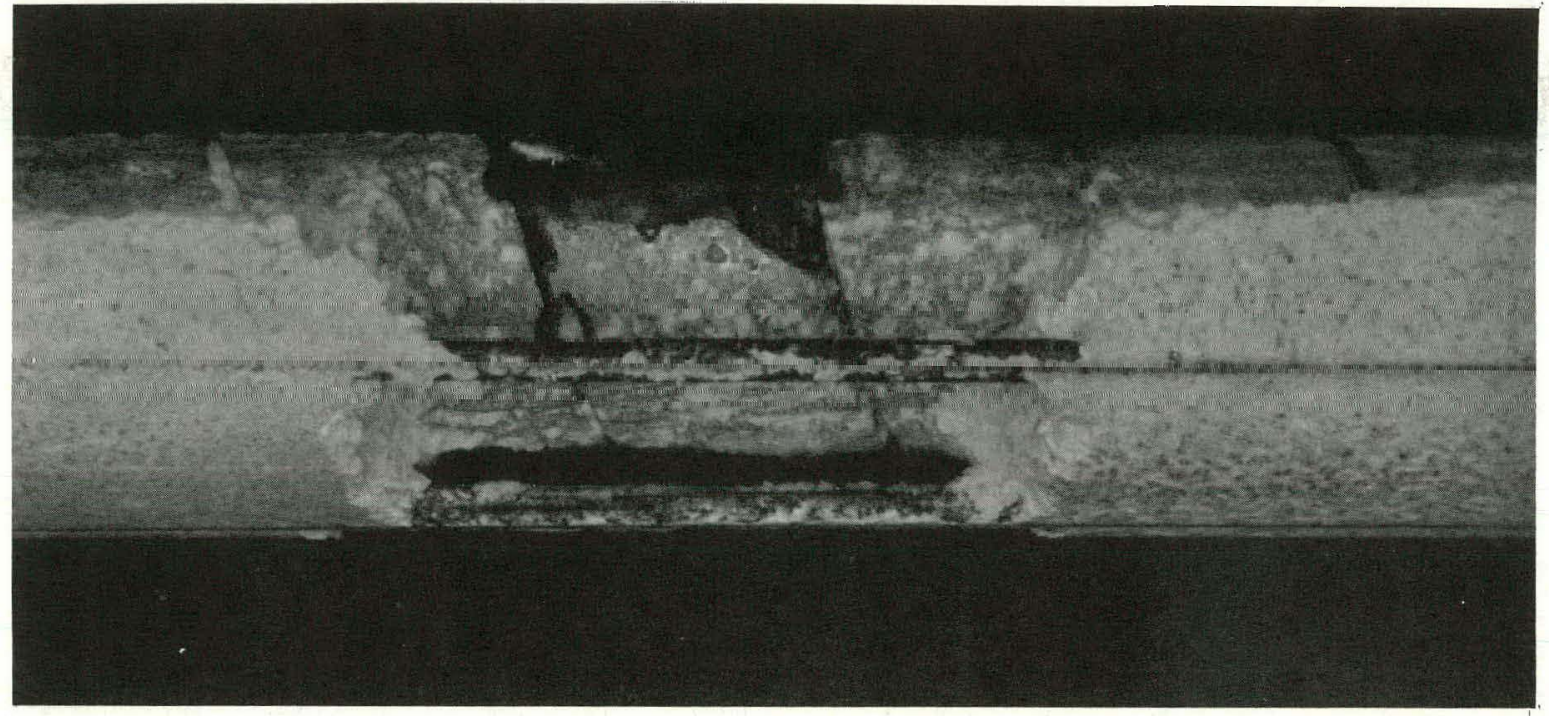

L353F

Figure 2. UNDERSIDE OF THE MELTED PLATINUM-8 TUNGSTEN ALLOY WINDING IN THE 7A PROTOTYPE HEATER. (Outer BN has been Scraped Away to Show the Damaged Winding; Small, Lengthwise Tubes are Thermocouple Tubes; 10X)

\section{Time/Temperature/Grain Size/Hardness Study}

Temperatures of $800,1100,1400$, and $1700^{\circ} \mathrm{C}$ and times of $1 / 4,1 / 2,1,2$, and 4 hours were selected for the study. Of the materials to be investigated, only the $6 \mathrm{~A}$ as-received ribbon and the $6 \mathrm{~A}$ heater winding had not been previously heat treated at $11000 \mathrm{C}$ for $1 / 2$ hour. The $6 \mathrm{~A}$ as-received ribbon was treated at $800^{\circ} \mathrm{C}$ to determine if the recovery process would take place at this temperature. All heat treatments were conducted in vacuum to prevent selective oxidation of the tungsten. Table 1 presents a matrix of the heat treatment conditions; details of the alloy specimens after various heat treatments are illustrated by the photomicrographs in Figures A-1 through A-20 (Appendix); Table 2 contains the hardness data.

The very highly worked $6 \mathrm{~A}$ as-received ribbon neither recovered nor recrystallized at $800^{\circ} \mathrm{C}$, as indicated by the hardness data in Table 2 and the microstructure in Figure A-1, View a. Because of the high degree of work, the recrystallized grain size after heating at $1100^{\circ} \mathrm{C}$ was small. The as-received $7 \mathrm{~A}$ and $8 \mathrm{~A}$ ribbons had been annealed for $1 / 2$ hour at $1100^{\circ} \mathrm{C}$ prior to receipt, and the grain size of these Iwu samples vas larger with respect to the $6 \mathrm{~A}$ sample when it had been similarly heat treated.

All three as-received ribbons showed substantial grain growth at $1400^{\circ} \mathrm{C}$, but the $7 \mathrm{~A}$ and 8A specimens, by means of a duplexed grain structure (Figures $A-4$, View b, and A-13, Views $b$ and $c$ ) gave evidence of rapid grain growth due to the critical strain introduced by slight bends resulting from handling the ribbon. The as-wound and as-wound-and-swaged $7 \mathrm{~A}$ ribbons and the as-wound $8 \mathrm{~A}$ ribbon showed considerable uniform grain growth at $1400^{\circ} \mathrm{C}$, but none of the duplex structures. 


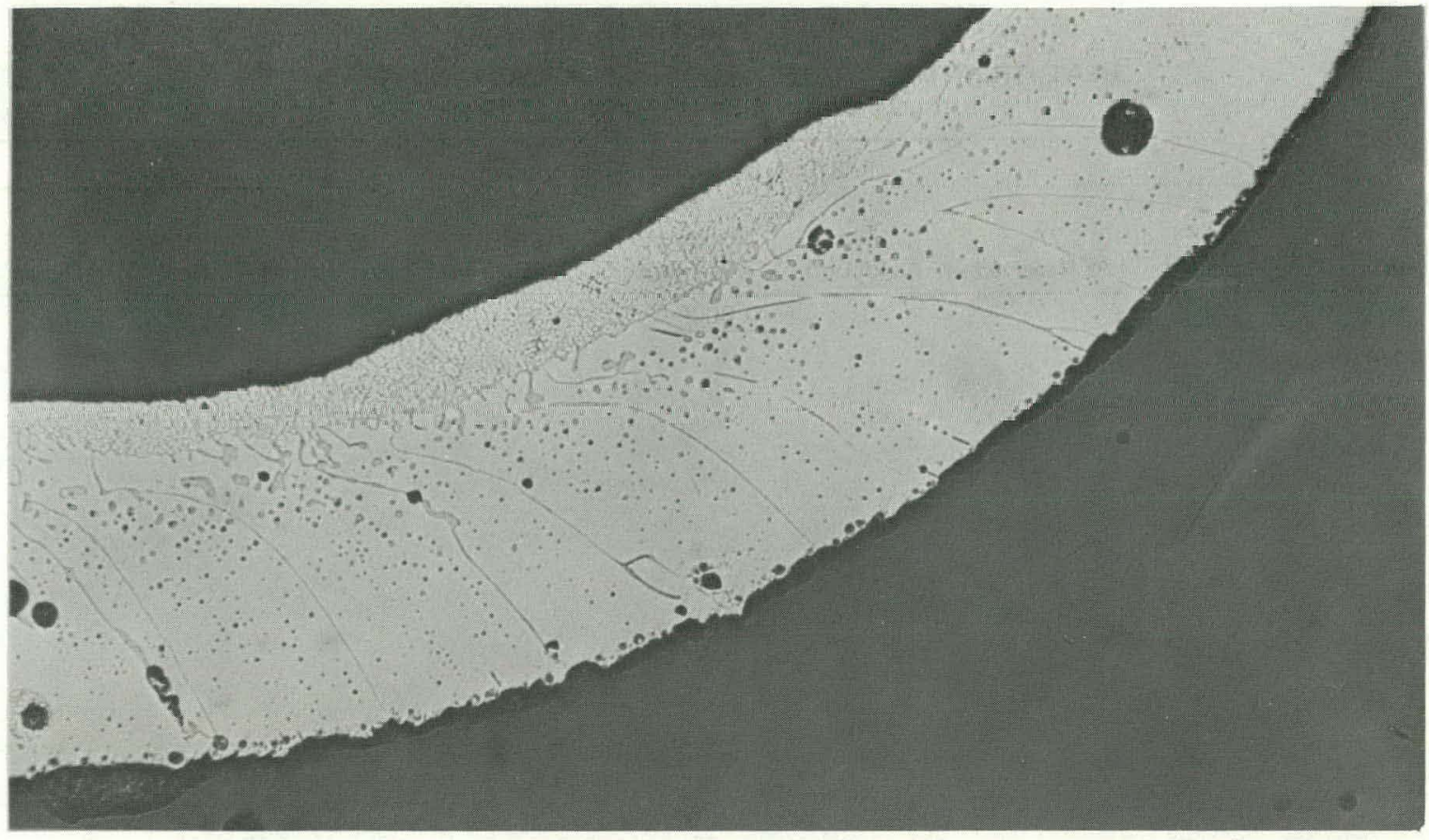

(a) Close to the Melted Area.

MS-75-0732-16

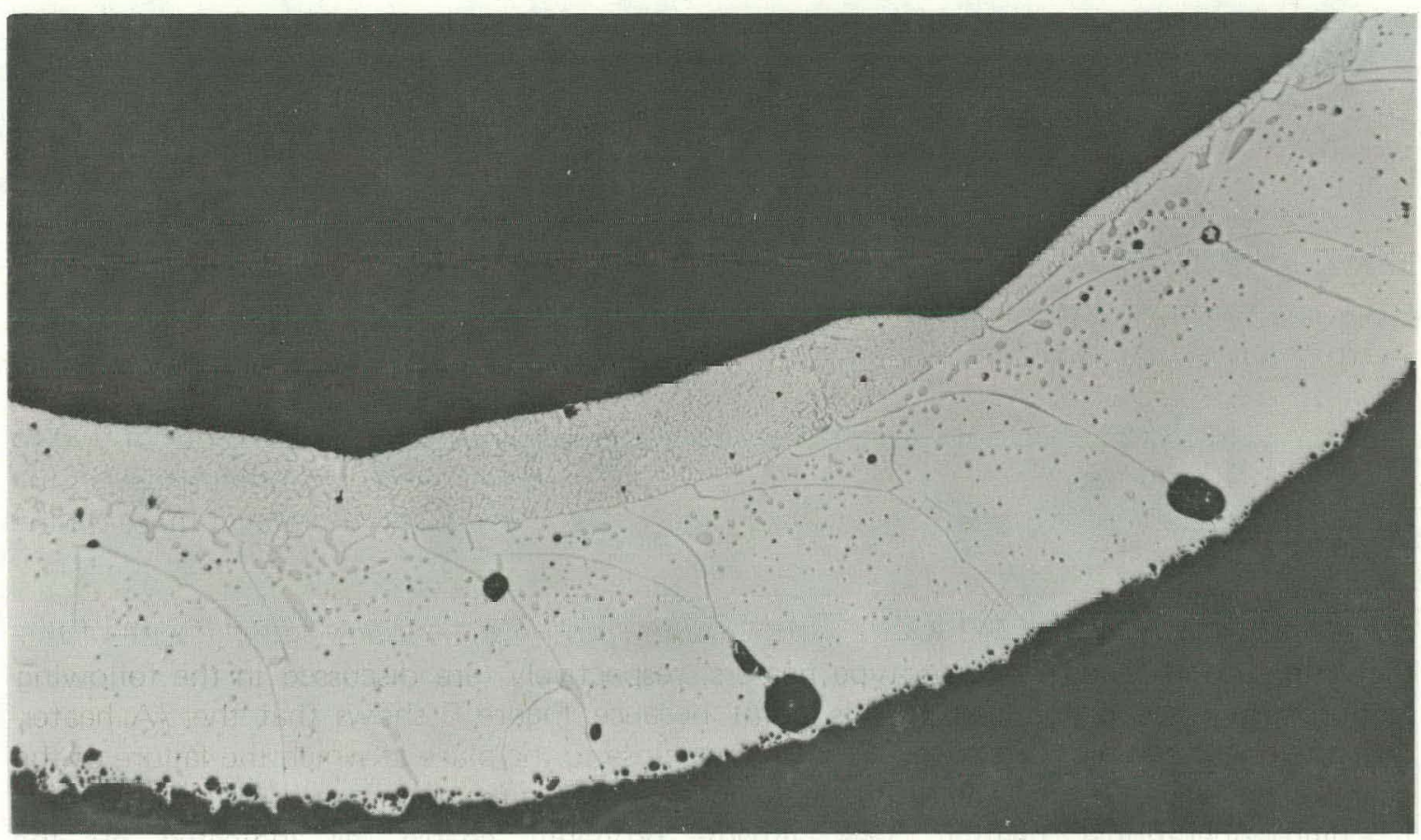

(b) Further $[0.5 \mathrm{~mm}(20 \mathrm{mils})]$ than View a from the Melted Area.

MS-75-0732-17

Figure 3. THICKENING OF THE PLATINUM-8 TUNGSTEN ALLOY WINDING CROSS SECTION, CAUSED BY FLOW OF MOLTEN ALLOY BETWEEN THE WINDING AND THE BORON NITRIDE CORE. (Unetched; 100X) 
Table 1

HEAT-TREATMENT MATRIX FOR THE PLATINUM-8 TUNGSTEN ALLOY GRAIN SIZE-HARDNESS STUDY

\begin{tabular}{|c|c|c|c|c|c|c|c|c|}
\hline \multirow{3}{*}{$\begin{array}{l}\text { Time } \\
\text { (hr) }\end{array}$} & \multicolumn{8}{|c|}{ Pt-8 W Alloy Ribbon Type and Source } \\
\hline & \multirow[b]{2}{*}{$\begin{array}{c}6 \mathrm{6} \\
\text { As Received }\end{array}$} & \multirow[b]{2}{*}{$\begin{array}{c}7 \mathrm{AA} \\
\text { As Received }\end{array}$} & \multirow[b]{2}{*}{$\begin{array}{c}7 A \\
\text { As Wound }\end{array}$} & \multicolumn{2}{|l|}{$7 \mathrm{~A}$} & \multirow[b]{2}{*}{$\begin{array}{c}8 A \\
\text { As Wound }\end{array}$} & \multirow[b]{2}{*}{$\begin{array}{c}6 \mathrm{~A} \\
\text { Heater }\end{array}$} & \multirow[b]{2}{*}{$\begin{array}{c}7 \mathrm{~A} \\
\text { Heater }\end{array}$} \\
\hline & & & & $\begin{array}{l}\text { As Wound } \\
\text { and Swaged }\end{array}$ & $\begin{array}{c}8 \mathrm{~A} \\
\text { As Received }\end{array}$ & & & \\
\hline \multicolumn{9}{|c|}{ At $800^{\circ} \mathrm{C}$} \\
\hline $1 / 4$ & $\sqrt{ }$ & & & & $\sqrt{ }$ & & & \\
\hline $1 / 2$ & $\sqrt{ }$ & & & & & & & \\
\hline 1 & $\sqrt{ }$ & & & & & & & \\
\hline $\begin{array}{l}2 \\
4\end{array}$ & $\begin{array}{l}\sqrt{ } \\
\sqrt{3}\end{array}$ & & & & $\sqrt{ }$ & & & \\
\hline \multicolumn{9}{|c|}{ At $1100^{\circ} \mathrm{C}$} \\
\hline $1 / 4$ & $\checkmark$ & & $\sqrt{ }$ & $\sqrt{ }$ & $\sqrt{ }$ & $\sqrt{ }$ & & \\
\hline $1 / 2$ & & & & & & & & \\
\hline 1 & $\sqrt{ }$ & & $\sqrt{ }$ & $\sqrt{ }$ & $\sqrt{ }$ & $\sqrt{ }$ & & \\
\hline $\begin{array}{l}2 \\
4\end{array}$ & $\sqrt{ }$ & $\sqrt{ }$ & $\sqrt{ }$ & $\sqrt{ }$ & $\sqrt{ }$ & $\sqrt{ }$ & $\sqrt{ }$ & $\sqrt{ }$ \\
\hline \multicolumn{9}{|c|}{ At $1400^{\circ} \mathrm{C}$} \\
\hline $1 / 4$ & $\sqrt{ }$ & $\sqrt{ }$ & $\checkmark$ & $\sqrt{ }$ & $\sqrt{ }$ & $\sqrt{ }$ & & \\
\hline 1 & $\sqrt{ }$ & $\sqrt{ }$ & $\sqrt{ }$ & $\sqrt{ }$ & $\checkmark$ & $\sqrt{ }$ & & \\
\hline 4 & $\sqrt{ }$ & $\sqrt{ }$ & $\checkmark$ & $\sqrt{ }$ & $\sqrt{ }$ & $\checkmark$ & $\sqrt{ }$ & $\sqrt{ }$ \\
\hline \multicolumn{9}{|c|}{ At $1700^{\circ} \mathrm{C}$} \\
\hline $1 / 4$ & $\sqrt{ }$ & $\sqrt{ }$ & $\sqrt{ }$ & $\sqrt{ }$ & $\sqrt{ }$ & $\sqrt{ }$ & & \\
\hline 1 & & & $\checkmark$ & $\sqrt{ }$ & $\checkmark$ & $\checkmark$ & & \\
\hline 2 & $\sqrt{ }$ & $\sqrt{ }$ & $\checkmark$ & $\sqrt{ }$ & $\checkmark$ & $\sqrt{ }$ & $\sqrt{ }$ & $\sqrt{ }$ \\
\hline
\end{tabular}

At $1700^{\circ} \mathrm{C}$, grain growth was excessive for all specimens, a behavior which is not unexpected for a relatively pure, single-phase alloy at temperatures approaching the melting range.

The 6A heater heat-treatment samples were obtained from about the midpoint of the 914-mm (36-in) length of 6A Heater 11. Figure A-18, Views a and b, show the microstructure of the winding as cut from the heater. Comparison with Figure A-1, View a, reveals that recrystallization is in the very early stages (which is verified by the hardness data in Table 2) so that it might be estimated that a winding temperature on the order of 900 to $1000^{\circ} \mathrm{C}$ had been reached. Effects of the 1100,1400 , and $1700^{\circ} \mathrm{C}$ heat treatments on the $6 \mathrm{~A}$ heater specimens (Figures A-18, View $\mathrm{c}$, and A-19, Views $\mathrm{a}$ and b) parallel those on the $6 \mathrm{~A}$ as-received ribbon.

Figures 4 and 5 which show the microstructure at depicted locations along the length of the first and second failed 7A prototype heaters, respectively, are discussed in the following section. They are introduced at this point because Figure 5 shows that the $7 \mathrm{~A}$ heater heat-treatment samples originated from an area close to the place at which the failure of the heater took place. This was an unfortunate choice because the grain size in this region, due to high operational heating, was already probably coarse, as indicated by the photomicrograph (Sample 3) taken only $44 \mathrm{~mm}$ (13/4 in) away from the failed area. This close proximity accounts for the difference in grain size (for equal $1100^{\circ} \mathrm{C}$, 4-hour treatments) from Figure A-20, View a, to Figures A-4, View a, A-6, View c, and A-10, View a. The grain sizes for all of the 7A specimens were essentially the same for the 1400 and 
$1700^{\circ} \mathrm{C}$ treatments. The possible significance of the integranular voids in Figure A-20, View C, is discussed in the section entitled: Simulation of Melting Platinum-8 Tungsten Alloy Ribbon Used in the Heaters, and Analysis of the Molten Failure Areas (Page 16). They were present at the same relative location in each of the four turns of the section of winding in that sample and may be associated with the overheating which occurred in the vicinity of the failure.

The hardness data in Table 2 show no unusual trends. As highly worked, the alloy has a diamond pyramid hardness (DPH) value in excess of 350 . Recrystallization at $1100^{\circ} \mathrm{C}$ drops the hardness to around 220. Grain growth, with its attendant decrease in the grain boundary area, and grain orientation effects cause further reductions in hardness such as those observed for specimens heat treated at 1400 and $1700^{\circ} \mathrm{C}$.

\section{Examination of the Platinum-8 Tungsten Alloy Winding from Two Failed 7A Prototype Heaters}

Platinum-8 tungsten alloy winding specimens for metallographic examination were cut from the locations along the lengths of the two failed $7 A$ prototype heaters illustrated in Figures 4 and 5. There were some similarities, but also inconsistencies with respect to the grain size of the two heaters; and, therefore, presumably with respect to the temperature seen at the same locations in both.

Table 2

DIAMOND PYRAMID HARDNESS VALUES OF PLATINUM-8 WEIGHT PERCENT TUNGSTEN ALLOY AFTER VARIOUS HEAT TREATMENTS

\begin{tabular}{|c|c|c|c|c|c|c|c|c|}
\hline \multirow[b]{2}{*}{$\begin{array}{l}\text { Time } \\
\text { (hr) }\end{array}$} & \multicolumn{8}{|c|}{ Type and Source of Ribbon and Diamond Pyramid Hardness Values ( $500 \mathrm{~g}$ Load) } \\
\hline & $\begin{array}{c}6 \mathrm{~A} \\
\text { As Received }\end{array}$ & $\begin{array}{c}7 \mathrm{~A} \\
\text { As Received }\end{array}$ & $\begin{array}{c}7 \mathrm{~A} \\
\text { As Wound }\end{array}$ & $\begin{array}{c}7 \mathrm{~A} \\
\text { As Wound } \\
\text { and Swaged }\end{array}$ & $\begin{array}{c}8 \mathrm{~A} \\
\text { As Received }\end{array}$ & $\begin{array}{c}8 A \\
\text { As Wound }\end{array}$ & $\begin{array}{c}6 \mathrm{~A} \\
\text { Heater }\end{array}$ & $\begin{array}{c}\text { 7A } \\
\text { Heater }\end{array}$ \\
\hline \multicolumn{9}{|c|}{$800^{\circ} \mathrm{C}$ Heat Treatment } \\
\hline $1 / 4$ & 378 & & & & 215 & & & \\
\hline $1 / 2$ & 360 & & & & & & & \\
\hline 1 & 365 & & & & & & & \\
\hline 2 & 370 & & & & & & & \\
\hline 4 & 360 & & & & 220 & & & \\
\hline \multicolumn{9}{|c|}{$1100^{\circ} \mathrm{C}$ Heat Treatment } \\
\hline $1 / 4$ & 219 & & 221 & 239 & 206 & 236 & & \\
\hline \multicolumn{9}{|l|}{$1 / 2$} \\
\hline 1 & 212 & & 220 & 210 & 214 & 237 & & \\
\hline 2 & 214 & & & & & & & \\
\hline 4 & 225 & 209 & 221 & 226 & 224 & 225 & 197 & 182 \\
\hline \multicolumn{9}{|c|}{$1400^{\circ} \mathrm{C}$ Heat Treatment } \\
\hline $1 / 4$ & 190 & 188 & 198 & 186 & 186 & 208 & & \\
\hline 1 & 193 & 201 & 182 & 192 & 201 & 196 & & \\
\hline 4 & 192 & 194 & 191 & 188 & 200 & 189 & 182 & 171 \\
\hline \multicolumn{9}{|c|}{$1700^{\circ} \mathrm{C}$ Heat Treatment } \\
\hline $1 / 4$ & 181 & 192 & 180 & 198 & 194 & 169 & & \\
\hline 1 & & & 178 & 189 & 194 & 207 & & \\
\hline 2 & 183 & 203 & 175 & 192 & 184 & 163 & 175 & 165 \\
\hline
\end{tabular}

(1) Hardness before heat treatment was $318 \mathrm{DPH}$. 


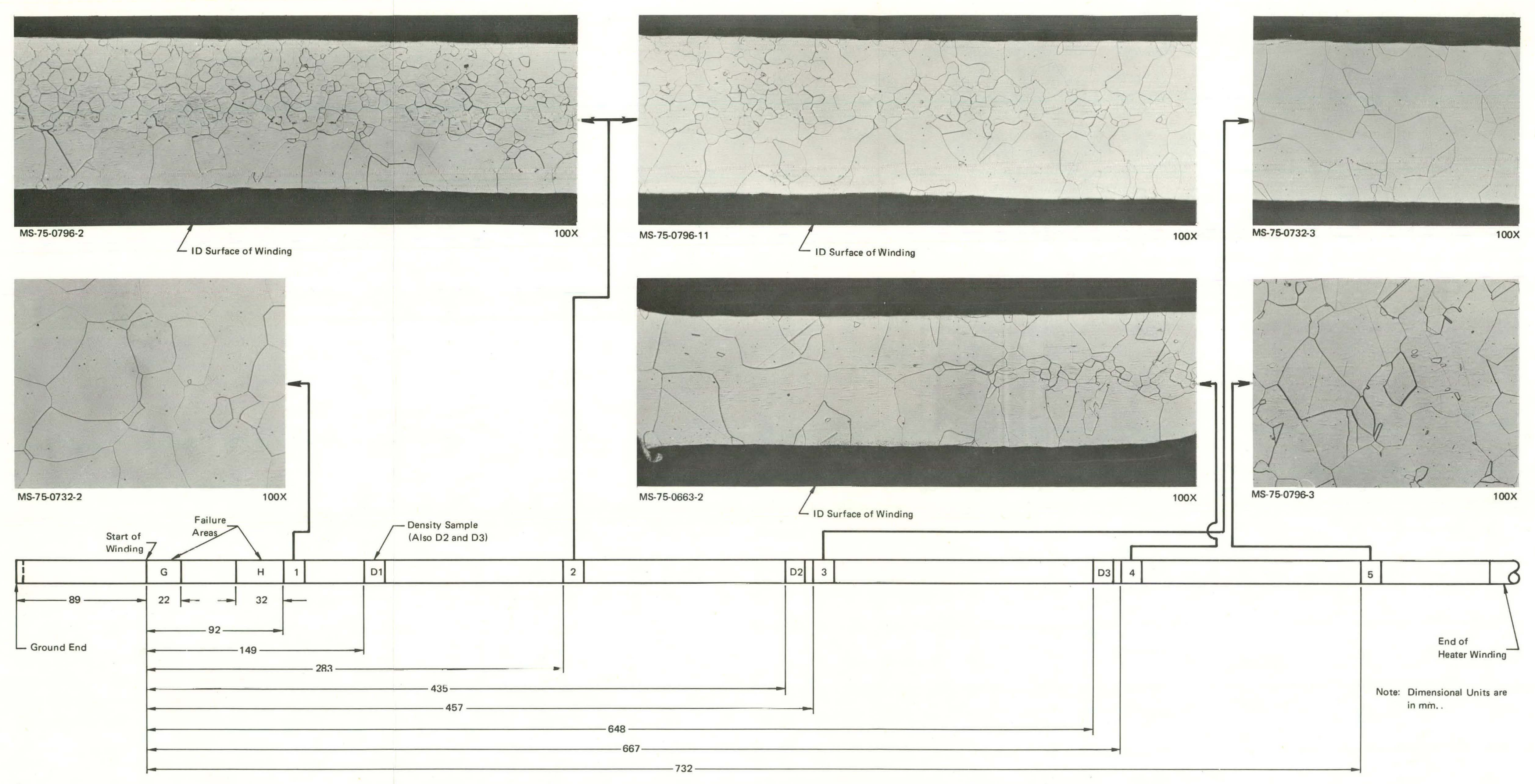

Figure 4. MICROSTRUCTURE OF THE PLATINUM-8 TUNGSTEN ALLOY WINDING AT DEPICTED LOCATIONS ALONG THE LENGTH OF THE FIRST FAILED 7A
PROTOTYPE HEATER. 


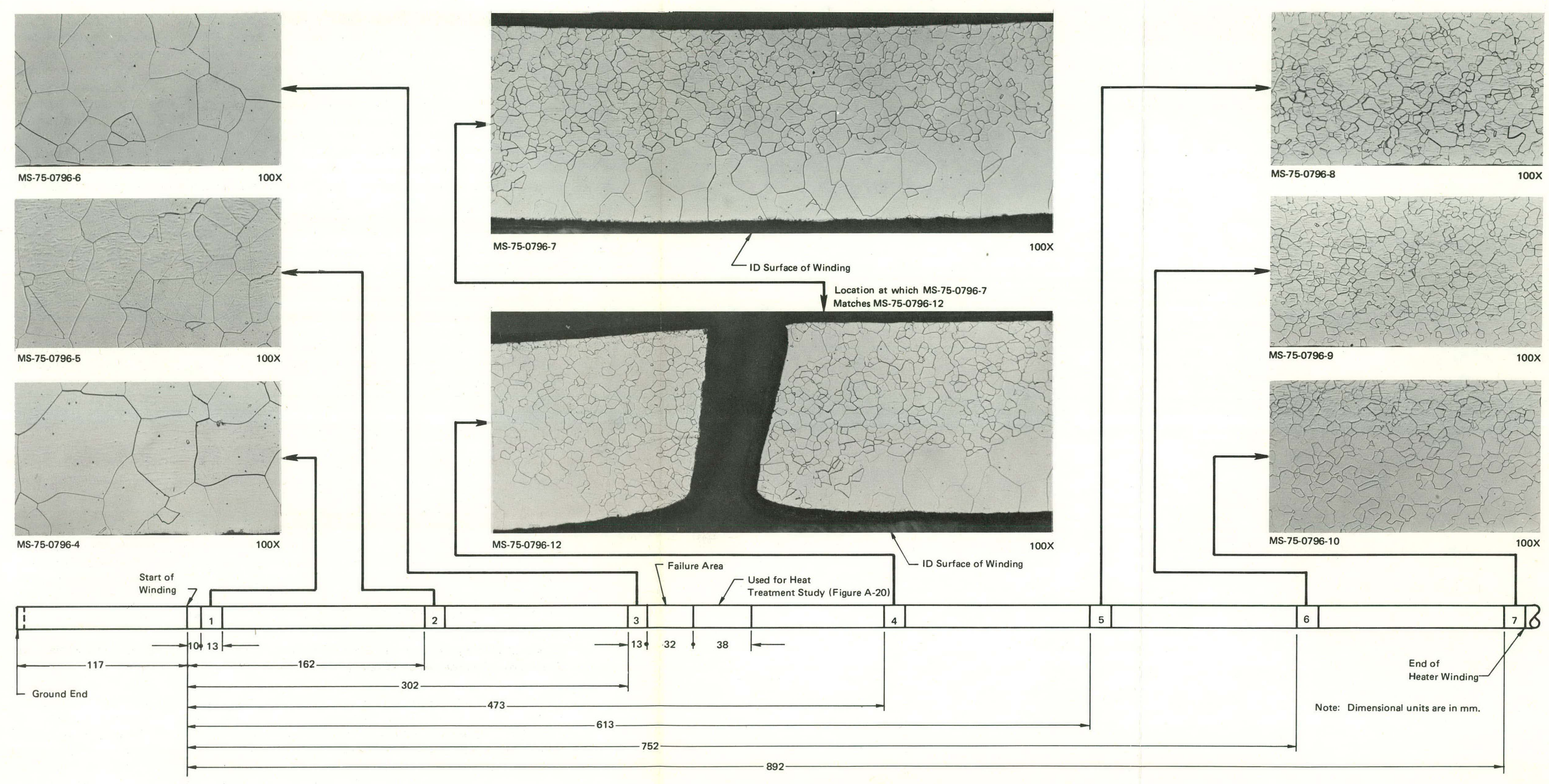

Figure 5. MICROSTRUCTURE OF THE PLATINUM-8 TUNGSTEN ALLOY WINDING AT DEPICTED LOCATIONS ALONG THE LENGTH OF THE SECOND FAILED 7A 
The grain size adjacent to the failure locations was the same for both heaters and, by comparison with the grain-size-study photomicrographs, could have been caused by long times at $1400^{\circ} \mathrm{C}$ or correspondingly shorter times at higher temperatures. Locations 1 and 2 , near the ground end of the second failed heater (Figure 5), were similarly coarse grained. The situations at the opposite ends of the heaters were different-the first heater (Location 5, Figure 4) showing coarse grains and the second heater (Locations 5, 6, and 7, Figure 5), fine grains. The following qualitative observations made during the cutting of these samples may aid in explaining this difference. At Location 5 (Figure 4) the outer BN insulation was observed to be very loose and powdery, almost to the point of pouring out of the sheath. On the other hand, at Locations 5 and 7 (Figure 5), it was noted that the outer BN insulation was extremely dense, tightly packed, and adhering to the alloy winding. The difference in $\mathrm{BN}$ density would greatly influence the conduction of heat from the element to the sheath and, therefore, the temperature of the element.

At Locations 2 and 4 (Figure 4) and Location 4 (Figure 5) similar structures were observed. The coarse-grain structure at the inside diameter of the winding and the fine grains at the outside diameter are evidence that a critical strain was induced during the winding of the coil. This behavior was not noticed in the temperature/grain-growth study, although the specimen orientation was not necessarily selected so as to reveal it. However, neither was it noticed when samples of as-wound 7A, as-wound and swaged $7 \mathrm{~A}$, and as-wound $8 \mathrm{~A}$ windings were annealed at $11000 \mathrm{C}$ for $1 / 2$ hour to specifically determine if this would occur. It seems that a temperature only slightly in excess of $1100^{\circ} \mathrm{C}$ is required since the fine-grain portion of the photomicrographs show a grain size which has grown little if any from that produced by an $1100^{\circ} \mathrm{C}$ anneal. It can be assumed then that the lack of inside-diameter coarse grains at Locations 5, 6, and 7 (Figure 5) indicates a maximum element temperature of less than $1100^{\circ} \mathrm{C}$.

Two other interesting observations can be made relative to the structure at these latter three locations. First, at both Locations 2 and 4 (Figure 4) within a few winding turns the structure changed from that shown in Photomicrograph 0796-2 to that shown in Photomicrographs 0796-11 and 0663-2. That is, grain coarsening also appeared at the outside-diameter surface, leaving a fine-grain region in the center (which may correspond with the neutral axis of the coiled winding) and then the entire cross section became coarse grained. Second, at Location 4 (Figure 5) at the ends of the ribbon, the fine-grain region is seen to extend through the thickness of the windings at their ends (Photomicrograph 0796-12). This behavior is a probable indication of a strain in excess of the critical strain which induced the grain coarsening in the center, inside-diameter region.

\section{Chemical Homogeneity of As-Received 6A and 7A Platinum-8 Tungsten Alloy Ribbon and Prototype 7A Heater Alloy Winding}

To investigate the possibility that alloying of the platinum and tungsten may not have been complete and thereby contributed to premature melting of the heater winding, the analytical capability of the EB microprobe was employed. Samples of 6A and 7A as-received alloy ribbon and a specimen from the first failed 7A prototype heater were used for analysis. Representative microstructures of the 6A and 7A as-received ribbon are those seen in Figures A-1, View a, and A-4, View a, respectively, while Photomicrograph 0663-2 (Figure 4 ) is the microstructure from an area on the 7A prototype heater specimen. 
Each specimen was scanned at two locations in the direction through its thickness. At 28- $\mu \mathrm{m}$ intervals along each scan, data were accumulated to perform quantitative analyses. Table 3 contains the data obtained. These figures show that the two 7A samples had the highest degree of homogeneity. Statistical evaluation of the data revealed that the 7A prototy.pe heater sample was homogeneous, the 7A as-received ribbon sample showed measurable inhomogeneity, and the $6 \mathrm{~A}$ as-received ribbon was significantly inhomogeneous. It was determined that fluctuations in the tungsten and platinum levels were not associated with grain boundaries.

Table 3

MEAN CHEMICAL COMPOSITION AND TWO-SIGMA LIMITS FOR INDIVIDUAL ELEMENTS BASED ON THE NUMBER OF DATA POINTS INDICATED

\begin{tabular}{|c|c|c|c|}
\hline \multirow{2}{*}{$\begin{array}{c}\text { Scan } \\
\text { Number }\end{array}$} & \multirow{2}{*}{$\begin{array}{l}\text { Number of } \\
\text { Data Points }\end{array}$} & \multicolumn{2}{|c|}{ Element Concentration (wt \%) } \\
\hline & & Tungsten & Platinum \\
\hline \multicolumn{4}{|c|}{ 7A Prototype Heater } \\
\hline 1 & 10 & $7.78 \pm 0.51$ & $88.51 \pm 1.03$ \\
\hline 2 & 11 & $7.88 \pm 0.96$ & $89.57 \pm 1.18$ \\
\hline \multicolumn{4}{|c|}{ 6A As-Received Ribbon } \\
\hline 1 & 10 & $6.05 \pm 1.61$ & $86.80 \pm 3.69$ \\
\hline 2 & 10 & $7.12 \pm 1.10$ & $88.81 \pm 1.92$ \\
\hline \multicolumn{4}{|c|}{ 7A As-Received Ribbon } \\
\hline 1 & 10 & $7.78 \pm 1.42$ & $88.41 \pm 2.31$ \\
\hline 2 & 9 & $8.00 \pm 0.81$ & $89.00+1.54$ \\
\hline
\end{tabular}

The reason that the sums of the weight percents of the two elements are biased from $100 \%$ is attributed to two effects: (1) a nonlinearity in the relation between primary-generated $X$-ray intensity and concentration, and (2) a difference in distribution of the generated $X$ rays between the alloy and standards which gives rise to a difference in the absorption effect, even if the absorption coefficients in the two materials are identical.

\section{Boron Nitride Density in the Annular Area of the Heaters}

Density measurements were made only on three specimens from the locations in the first failed 7A prototype heater shown in Figure 4. As noted in other sections of this report, qualitative observations have been made which indicate that considerable variation exists in the density of the BN packed into the annular volume between the sheath and winding. It has also been noted that the BN core rods do not crush as desired, and may be undersize such that a radial gap exists between the core rod and the winding inside diameter.

The three samples (D1, D2, and D3) were sections from the heater about $13 \mathrm{~mm}(1 / 2 \mathrm{in})$ in length. To determine the annular BN density, the following steps were performed by the Y-12 Analytical Laboratory:

1. Bulk density was measured by mercury immersion.

2. True density and porosity was measured using the mercury porosimeter. 
3. Mercury was evaporated from the sample.

4. Specimen was disassembled and the density of the BN core rod, Pt-8 W alloy winding, and stainless steel sheath was measured.

5. By difference, the bulk density of the annular BN was obtained.

Table 4 contains the analytical data obtained for the three samples analyzed. The composite bulk density varied for two reasons: (1) a gap was present in the BN core rod of Sample D1, and (2) the pitch of the Pt-8 W alloy heating-element winding varied from sample to sample, resulting in varying amounts of alloy in each sample. The second reason also applies to the differences in the metal-part densities. The annular BN bulk densities show some variation from sample to sample, but, overall, are a somewhat low percentage of theoretical.

\section{Simulation of Melting Platinum-8 Tungsten Alloy Ribbon Used in the Heaters, and Analysis of the Molten Failure Areas}

As noted under WORK DONE PRIOR TO THIS STUDY and Investigation of the Second 7A Prototype Heater Failure, melting of the Pt-8 $\mathrm{W}$ ribbon was associated with the failures of two 7A prototype heaters. However, that a more involved situation than simple melting existed was attested to by the presence of tungsten-free areas in a melted zone of the first failed heater. It would not be expected that unmelted platinum, the lower-melting component, would remain through the melting/

Table 4

DENSITY DATA ON SECTIONS FROM THE FIRST FAILED 7A PROTOTYPE HEATER

\begin{tabular}{lrrr}
\hline & \multicolumn{3}{c}{ Sample Identification (1) } \\
\cline { 2 - 4 } \multicolumn{1}{c}{ Analysis } & D1 & D2 & D3 \\
\hline Bulk Density (g/cm 3 ) & & & \\
Composite & 4.75 & 5.51 & 5.15 \\
BN Core Rod & 2.03 & 1.98 & 2.08 \\
Annular BN & 1.68 & 1.70 & 1.61 \\
Metal Parts (2) & 10.48 & 11.49 & 10.99 \\
Porosity (\%) & & & \\
Composite & 15.62 & 13.85 & 15.44 \\
BN Core Rod & 11.44 & 13.37 & 10.63 \\
Annular BN & 26.84 & 25.99 & 29.66 \\
Metal Parts (2) & - & - & - \\
Real Density (g/cm 3 ) & & & \\
Composite & & & \\
BN Core Rod & 5.63 & 6.39 & 6.09 \\
Annular BN & 2.29 & 2.29 & 2.33 \\
Metal Parts (2) & 2.30 & 2.29 & 2.29 \\
Percent of Real Density & 10.48 & 11.49 & 10.99 \\
BN Core Rod & & & \\
Annular BN & 89 & 86 & 89 \\
\hline
\end{tabular}

(1) See Figure 4.

(2) Parts consisted of the Pt-8 W alloy winding and stainless steel sheath. alloying process used in ribbon fabrication, nor would areas essentially completely free of tungsten occur as a result of constitutional supercooling upon the freezing of a molten-alloy heater winding. It would be suggested, then, that the unusual melting behavior might be explained by a high-temperature interaction between the alloy and its boron nitride environment. Several experiments were undertaken in an attempt to shed light on the question of whether a reaction would occur between $\mathrm{BN}$ and the molten or solid alloy.

To investigate the solid/solid reaction possibility, runs were made in the Y-12 Plant Laboratory differential thermal analysis (DTA) apparatus. In the first run, a piece of the spiral winding around the $\mathrm{BN}$ core rod was heated to $1600^{\circ} \mathrm{C}$, the maximum capability of the equipment in a beryllium oxide crucible in an argon atmosphere. No reaction occurred. On the premise that a contaminant might be a factor in the reaction, a small quantity of 
boric oxide was placed in contact with the alloy/BN composite and the materials were reheated under the same conditions. Again, no reaction took place. A second piece of alloy winding around the $\mathrm{BN}$ core was then placed in contact with a small amount of elemental boron and reheated as before. At about $1385^{\circ} \mathrm{C}$ an exothermic reaction began, but was incomplete at $1600^{\circ} \mathrm{C}$, the maximum temperature attained. Unfortunately, the cooling was not followed by the differential thermocouple, so the freezing temperature was not determined. The alloy had the appearance of partial melting, and its microstructure (as seen in Figure 6) indicates that this action occurred. The darker phase, though present in greater amounts, appears to be similar to that observed in Figure 7, the microstructure of a melted area in the Pt-8 $\mathrm{W}$ alloy from a failed 7A prototype heater.

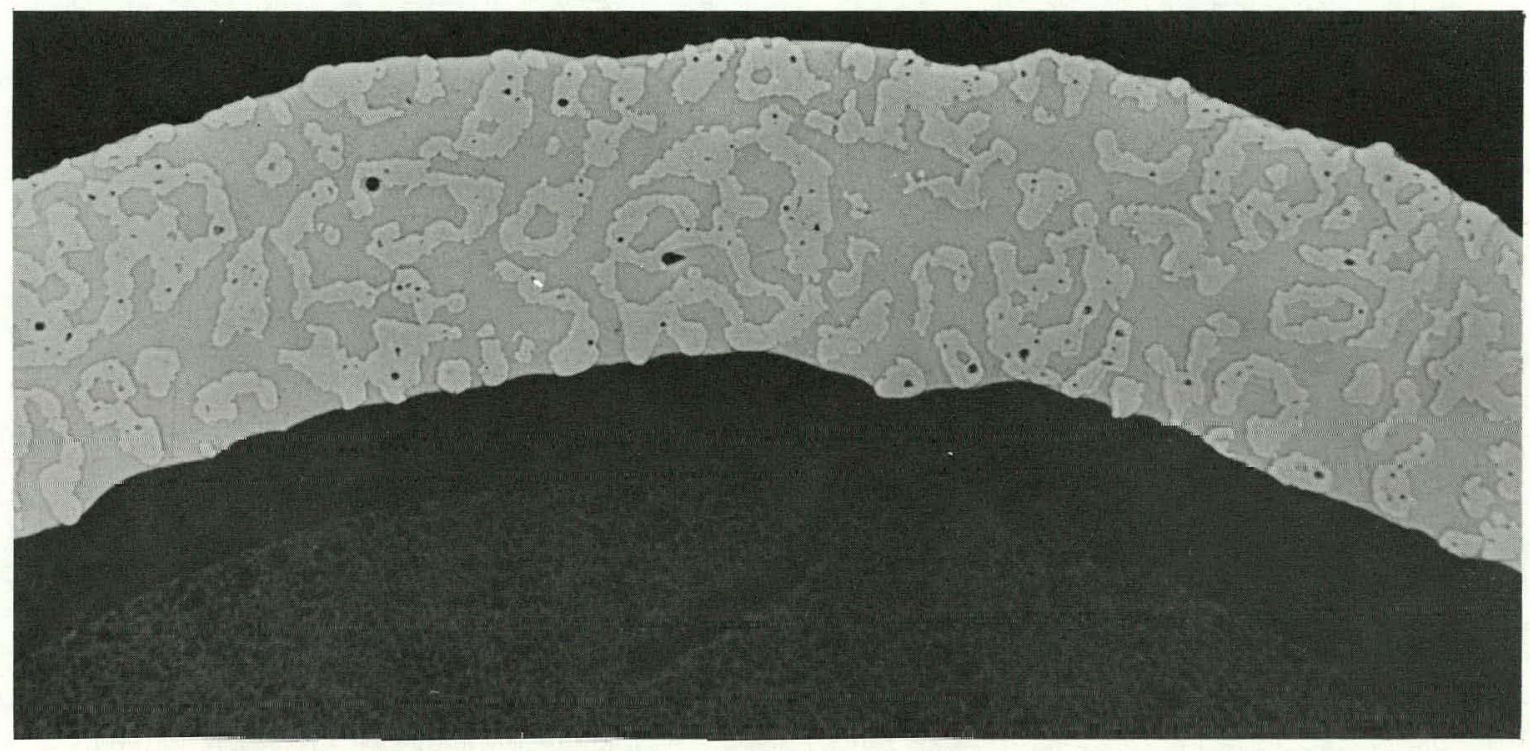

MS-75-0796-1

Figure 6. STRUCTURE OF THE PLATINUM-8 TUNGSTEN ALLOY AFTER REACTION WITH BORON AT 1385 - $1600^{\circ} \mathrm{C}$ (Unetched; 100X)

Associated work was performed on the ion-beam microprobe mass analyzer (IMMA) in an attempt to determine the constituents of the dark phase formed in the melted Pt- $8 \mathrm{~W}$ alloy. The specimen analyzed in this case was the melted section of ribbon whose microstructure appears in Figure 7.

By computer reduction of the ion-microprobe data it is possible to obtain roughly quantitative estimates of material composition, but the low degree of confidence associated with these estimates must be borne in mind. Analysis of an apparently unmelted area, free of the darker phase (such as that in the lower right corner of Figure 7) showed (in weight percent): 84 platinum, 15 tungsten, 0.7 rhodium, 0.2 ruthenium, 0.2 iron, and 0.04 boron. Over the two-phase area in the left central part of the figure, increases in boron, aluminum, and silicon were observed, with little change in tungsten. Figure 8 is an area of the specimen containing grain boundaries and particles of the second-phase material. It is of interest that the second-phase area (Particle A) appears, itself, to be more than one phase. An analysis of it showed it to be devoid of tungsten, ruthenium, and iron, and much richer in boron and silicon. The analysis obtained was (in weight percent): 84 platinum, 14 boron, 1.3 silicon, 


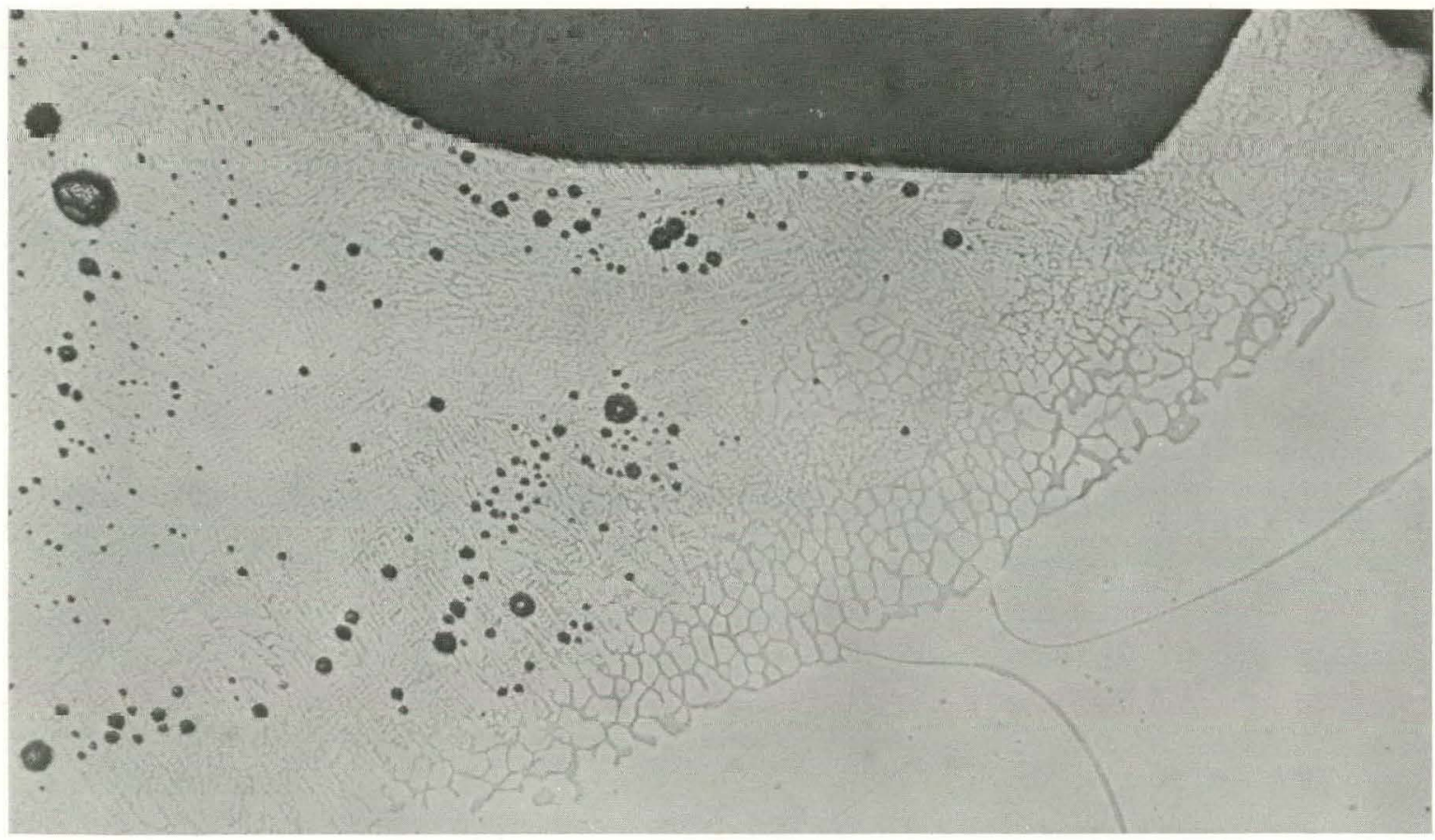

MS-75-0684-3

Figure 7. SECTION THROUGH THE PLATINUM-8 TUNGSTEN ALLOY RIBBON WHICH MELTED AT THE POINT OF FAILURE OF 7A PROTOTYPE HEATER 1. (Unetched; 250X)

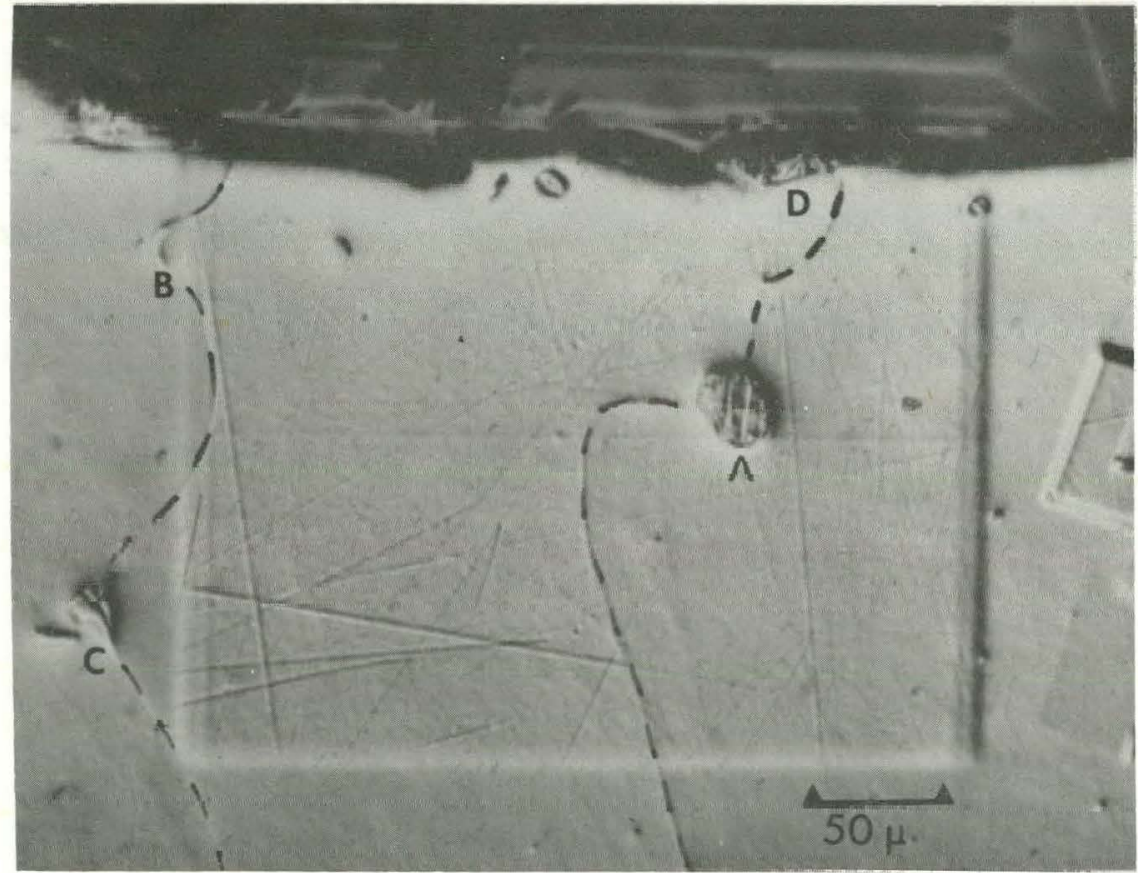

165180

Figure 8. POLISHED SECTION OF PLATINUM-8 TUNGSTEN ALLOY THAT WAS ADJACENT TO THE MELTED AREA PICTURED IN FIGURE 7. (The Sputtered Area, Grain Boundaries, and Second-Phase Particles Analyzed are Shown) 
and 0.3 rhodium. Secondary-ion images of boron, tungsten, and platinum appear in Figure 9. These photographs do not cover the entire area in Figure 8. Boron is concentrated in Particle $A$ and in the grain boundary. Area $D$ also appears to be a second-phase area enriched in boron. Other spots along the edge are boron nitride. Tungsten is deficient in the grain boundary and in Particle A, and platinum is less abundant in these same areas.

Adjacent to the areas of the Pt-8 $\mathrm{W}$ alloy windings, where melting occurred, there was growth of grains to very large sizes and intergranular cracks through the wound ribbon. Figure 10 is a scanning electron micrograph of a representative intergranular fracture area which was located about $10 \mathrm{~mm}$ from the previously discussed melted area. The edges of the grains are sharp, with no suggestion of melting. The ion microprobe was used to examine several facets from the mating half of this fracture, but not necessarily those mating with the facets pictured in Figure 10. The fractured surfaces showed decreased tungsten and increased boron, aluminum, and silicon with respect to the platinum when compared with the bulk material. On some of the fracture sites, sodium, potassium, and calcium were also more abundant than normal.

\section{DISCUSSION OF RESULTS}

The objective of this study has been to produce data and study heater failures in order to understand the reasons for the overheating and melting of the Pt-8 $\mathrm{W}$ alloy in failed $7 \mathrm{~A}$ prototype heaters. Data presented not only in this report but also obtained in previous failure analyses have provided information upon which to postulate the causative factors involved in the failure process.

Examination of the failure of the second 7A prototype heater showed it to be no different from the first except that the loss of contact between the winding and the BN core was due to excessive radial clearance between the two rather than to a lengthwise gap in the core. Similarity of the failures points out the necessity for adequate winding-core contact over the entire heater length to prevent localized hot spots and even melting in the winding.

Neither failure occurred at the location of highest heat flux (ie, the region of least spacing between winding turns), so it can be assumed that locally abnormal conditions of heater manufacture contributed most to the failures. It is known from a previous study that the $\mathrm{BN}$ core rods are most susceptible to cracking in the area of the winding where the pitch is greatest, a situation which presents a potential for damage to the winding by overheating in a low-heat-flux location.

There was no measured low-density region in the outer, annular BN associated with either 7A prototype heater failure. The density data in Table 4 show that specimens from the first failed heater had a fairly low, but uniform annular BN density. However, the qualitative observations made in connection with the examination of the alloy windings from the two heaters (see the section on Examination of Platinum-8 Tungsten Alloy Winding from Two Failed 7A Prototype Heaters, Page 11) indicate that wide variations in annular BN density may exist.

The time/temperature/grain size/hardness study yielded information which was useful in relating temperature with the variability in grain size along the windings of the failed 


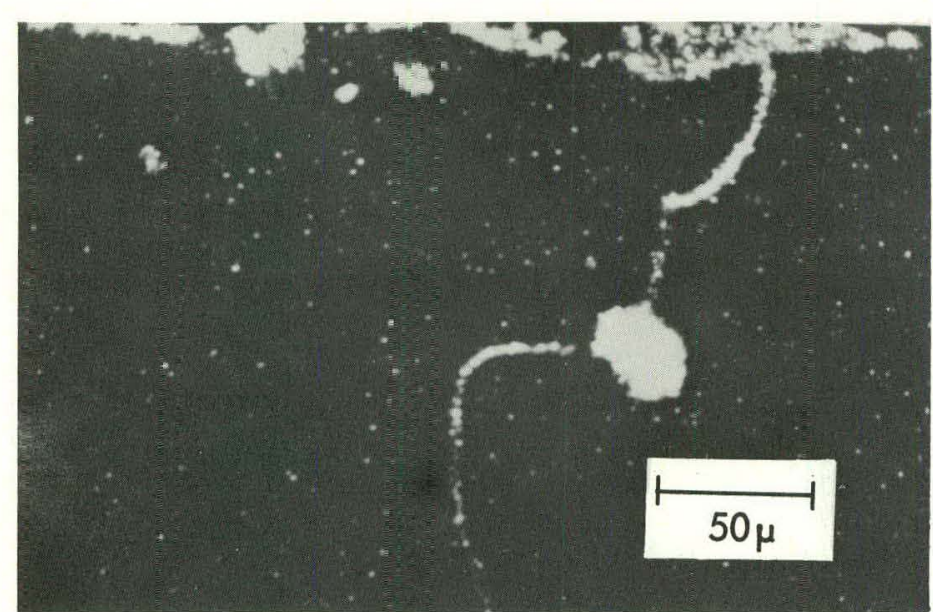

(a) Secondary-Ion Image of $11 \mathrm{~B}^{+}$.

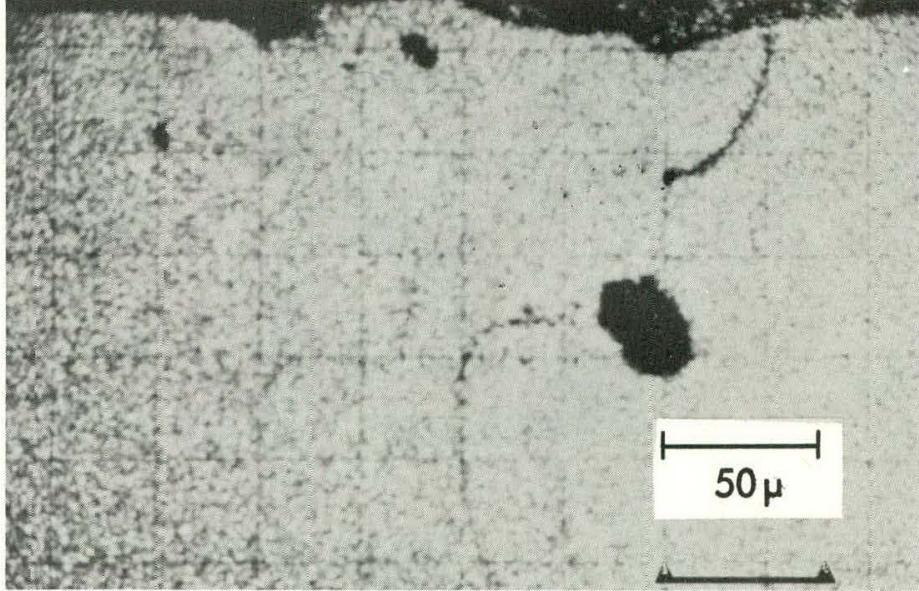

(b) Secondary-Ion Image of $\mathrm{W}^{+}$.

165179

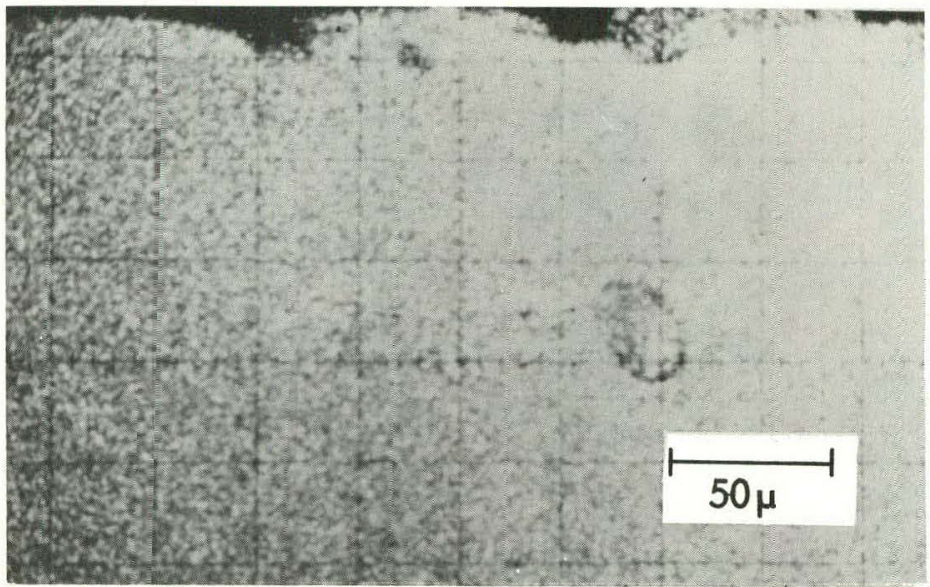

(c) Secondary-Ion Image of $195 \mathrm{pt}^{+}$.

165182

Figure 9. SECONDARY-ION IMAGES OF PLATINUM-8 TUNGSTEN ALLOY CONTAINING A SECOND PHASE IN PARTICLES AND GRAIN BOUNDARIES. 


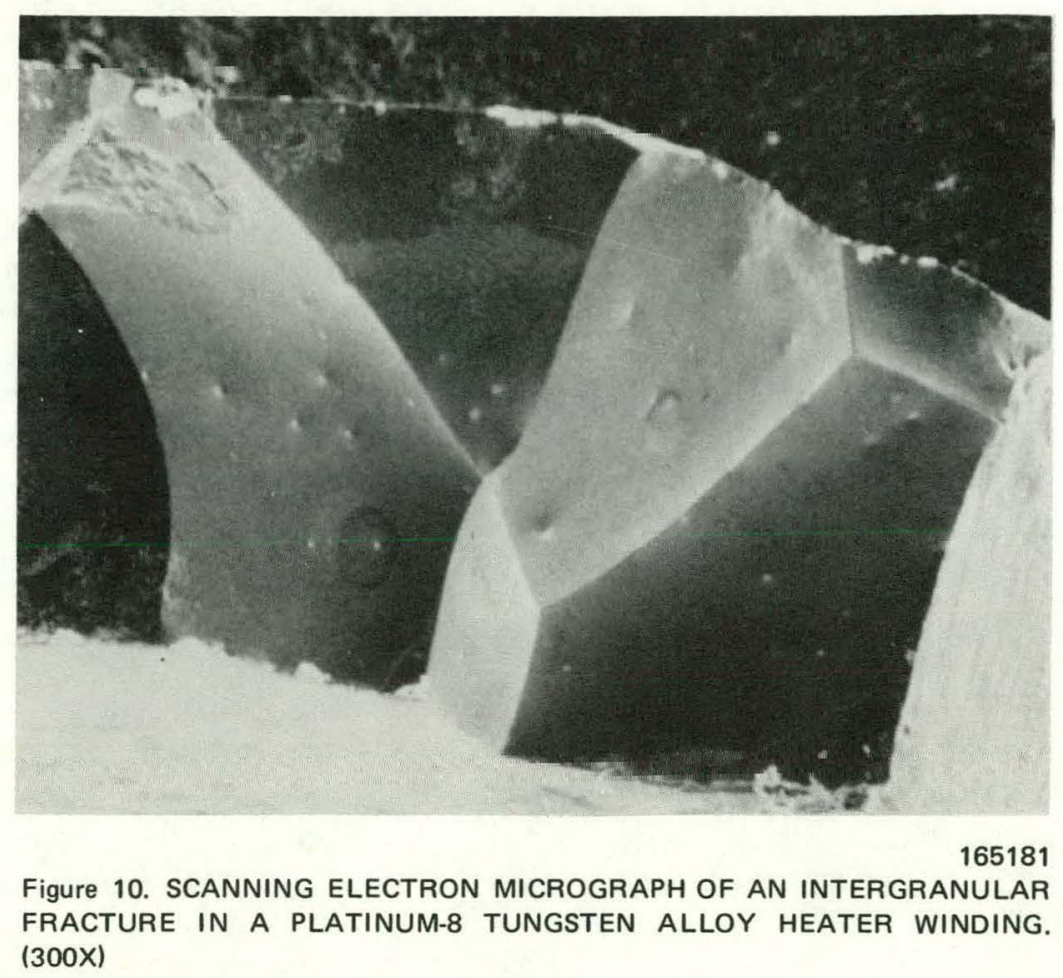

heaters. However, due to the $300^{\circ} \mathrm{C}$ range between successive heat-treatment temperatures, it did not pick up the critical grain-growth behavior in the as-wound heaters shown in Figures 4 and 5. Information from the study also indicated that the selected annealing treatment of $1100^{\circ} \mathrm{C}$ for $1 / 2$ hour was suitable in that complete recrystallization occurred under these conditions. The hardness data of Table 2 not only indicate the hardness levels of worked and annealed structures, but also show the reduction in hardness to be expected with increasing grain size. Only in areas immediately adjacent to the failures were grain sizes observed which approached those produced by the $1700^{\circ} \mathrm{C}$ treatment in the study. This observation suggests that grain growth, per se, was not a cause of failure.

The heavily worked as-received $6 \mathrm{~A}$ ribbon maintained a smaller grain size through the $1400^{\circ} \mathrm{C}$ treatments than did the annealed as-received 7A and the as-wound 7A and $8 \mathrm{~A}$ ribbons. This factor should be borne in mind in the fabrication of future heaters, both because of the reduced grain size and because the problem with respect to critical grain growth would be eliminated. Of course, the critical-grain-growth situation could also be eliminated in annealed windings by introducing a greater-than-critical amount of strain (eg, about $10 \%$ ) into the structure after annealing. However, the high rate of work hardening possessed by this alloy might cause difficulty in coil winding even at this strain level.

In an examination of the microstructure at various locations along the lengths of the windings in the two failed heaters (Figures 4 and 5), the principal significance of the totally coarse-grained areas is that they indicate that temperatures possibly as high as $1300-1400^{\circ} \mathrm{C}$ were reached in localized regions of the heater winding. This conclusion assumes that the effect of time at temperature is many times less influential on grain size than is the effect of temperature. 
There is the possibility that the $1300-1400^{\circ} \mathrm{C}$ estimate may be somewhat high in light of the critical-grain-growth behavior shown in Figure 5. Grain sizes on the order of those produced at $1400^{\circ} \mathrm{C}$ in the as-wound $7 \mathrm{~A}$ and $8 \mathrm{~A}$ ribbons in the grain-growth study were evidently produced by critical grain growth at somewhat above $1100^{\circ} \mathrm{C}$ in the Specimen 4 area in Figure 5. This behavior suggests that the $1400^{\circ} \mathrm{C}$ structures in the specimens in the grain-growth study may have actually been produced at lower temperatures, with only a slight increase in grain size as the temperature was raised to $1400^{\circ} \mathrm{C}$.

The lack of symmetry in the grain structures as a function of length along the two heaters would appear to reflect a lack of consistency in the manner in which the core and annular $\mathrm{BN}$ are prepared and placed in the heater. This inconsistency would result in variable radial thermal conductivity throughout the heater and the possibility of localized overheating which would be revealed by grain growth and possible melting.

No information was obtained which would indicate that gross compusiliumal inhomogeneities existed within the as-received or as-wound alloy ribbon. Although the eler.trnn-heam microprobe revealed some significant variations in tungsten content, no areas essentially free of tungsten were seen in the undamaged ribbon, either by the microprobe or in the many metallographic sections prepared during the course of the investigation. The tungsten-free areas observed in the ion-probe analysis, then, are unquestionably the consequence of the melting which occurred in the course of the failures.

The manner in which melting took place is not known. There are several possibilities by which it may have occurred. First, the ribbon may have been heated to its melting point, at which time it reacted with adjacent $\mathrm{BN}$ with the formation of a low-melting Pt/B eutectic and the liberation of nitrogen gas. Second, in spite of the lact that experimentally no reaction was observed between the alloy and $\mathrm{BN}$ at $16000 \mathrm{C}$, longer times at highly elevated temperatures might have caused sufficient decomposition of the $\mathrm{BN}$ to provide free boron for a reaction. And third, an impurity such as silicon, which is present in BN, or phosphorus, both of which form low-melting eutectics with platinum, might have contributed to the failure process in some manner. For any of the three possibilities to have occurred, the solubilities of these elements in platinum would have to be very low.

Using estimates of the amount of alloy melted and platinum/tungsten phase diagram data, it appears that only a very small quantity of boron (on the order of a milligram) is required to cause the melting observed at a point of failure. For this reason, and because it both eliminates the need for the ribbon to reach its melting point and allows for the passage of a period of time before failure, the second premise, with a possible contribution from the third, appears to be the most probable.

\section{CONCLUSIONS}

The following conclusions can be stated as a result of this study:

1. The primary cause of 7A prototype heater failure appears to have been a built-in, localized area of no contact between the heater winding and $\mathrm{BN}$ core such that the rate of heat conduction from the winding was reduced. As a consequence, the ribbon 
overheated and reacted with either the $\mathrm{BN}$ or elemental boron from decomposed $\mathrm{BN}$, and/or silicon and aluminum impurities in the BN to produce a low-melting eutectic mixture.

2. Excessive grain growth occurred only in areas adjacent to the high-temperature failure locations and resulted in single grain boundaries completely through the alloy ribbon. Silicon and aluminum impurities associated with the failure zone contributed to intergranular fracture adjacent to the melted areas. Grain growth, per se, was not, however, believed to a direct cause of failure.

3. Critical grain growth apparently occurred at the ID surface of the 7A prototype heating coils wound from annealed Pt-8 W ribbon; when the winding was heated to a temperature somewhat in excess of $1100^{\circ} \mathrm{C}$.

4. The highly worked $6 \mathrm{~A}$ alloy ribbon yielded a considerably finer as-annealed grain size than was observed in the 7A and $8 A$ ribbons. The problem of critical grain growth was not encountered in the 6A ribbon because it was not annealed before winding. The small strains due to handling and winding were simply additive to the working which was present from cold rolling.

5. Although some variability in tungsten content in the alloy ribbon was revealed by the EB microprobe, the existence of essentially tungsten-free areas was a result of the melting interaction which caused the ribbon failures. It was not determined what happened to the tungsten originally present in the melted areas.

\section{RECOMMENDATIONS}

Work should be done to discover the mechanism by which the melting of Pt-8 W alloy in contact with BN occurs. This study would include investigation of the stability of $\mathrm{BN}$ as a function of temperature, time; and atmosphere; the temperature of reaction between boron and the Pt- $8 \mathrm{~W}$ alloy, and the disposition of the tungsten after the reaction. 


\section{ACKNOWLEDGEMENTS}

It should be noted that S. S. Cristy and J. F. McLaughlin of the Laboratory Development Department performed the ion-microprobe and electron-beam-microprobe investigations, respectively. The large number of metallographic specimens were prepared by $\mathrm{H}$. C. East of the Metallurgical Services Department. 
APPENDIX

PHOTOMICROGRAPHS OF THE ALLOY SPECIMENS AFTER VARIOUS HEAT TREATMENTS 
THIS PAGE

\section{WAS INTENTIONALLY LEFT BLANK}



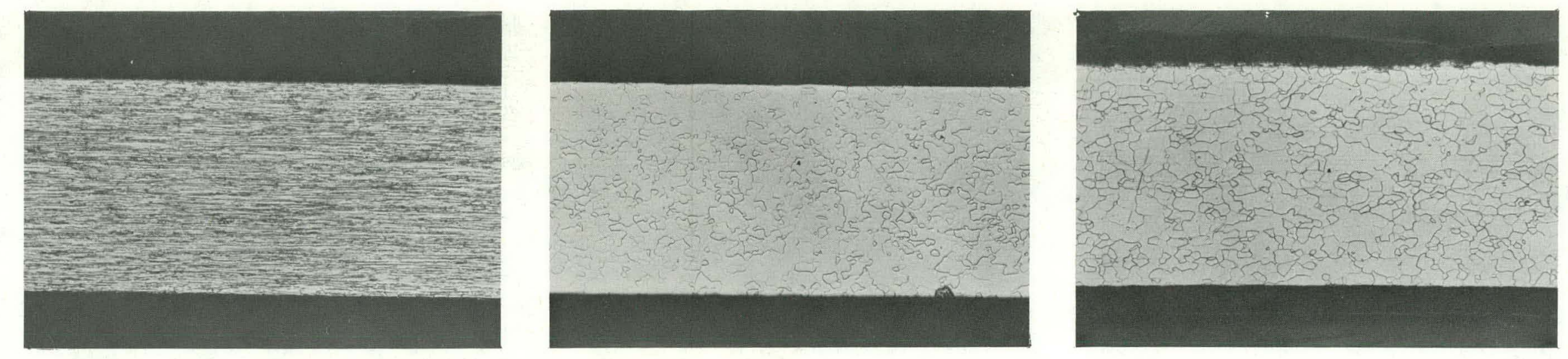

MS-75-0732-4 (d) At $1100^{\circ} \mathrm{C}$ for $2 \mathrm{Hr}$

MS-75-0732-5

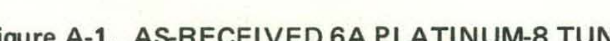
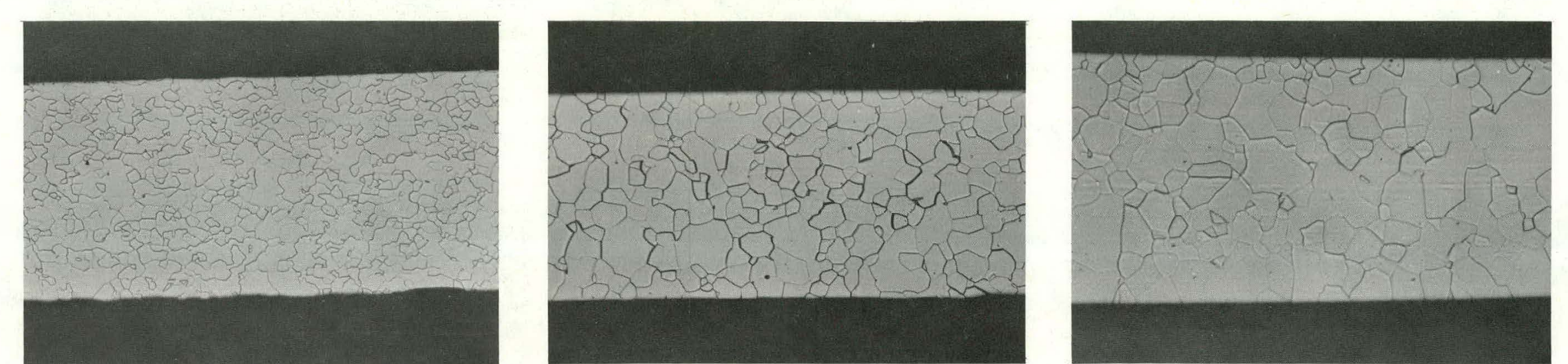

(a) At $1100^{\circ} \mathrm{C}$ for $4 \mathrm{H}$

MS-75-0732-6 (b) At $1400^{\circ} \mathrm{C}$ for $1 / 4 \mathrm{H}$.

Ms-75-0743-2 (c) At $1400^{\circ} \mathrm{C}$ for $1 \mathrm{Hr}$.

Ms-75-0743-1

Figure A-2. ASRECEIVED GA PLATINUM-8 TUNGSTEN ALLOY RIBBON AFTER VARIOUS HEAT TREATMENTS. (100X)

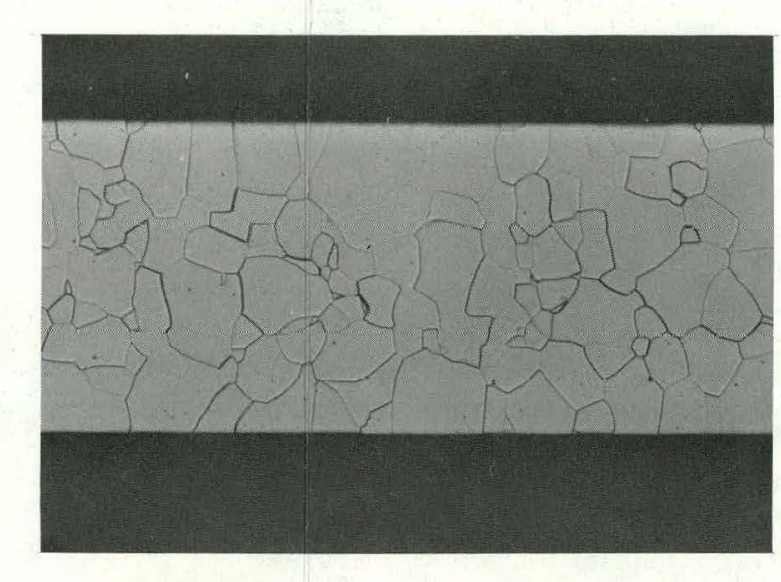

S-75-0743-3
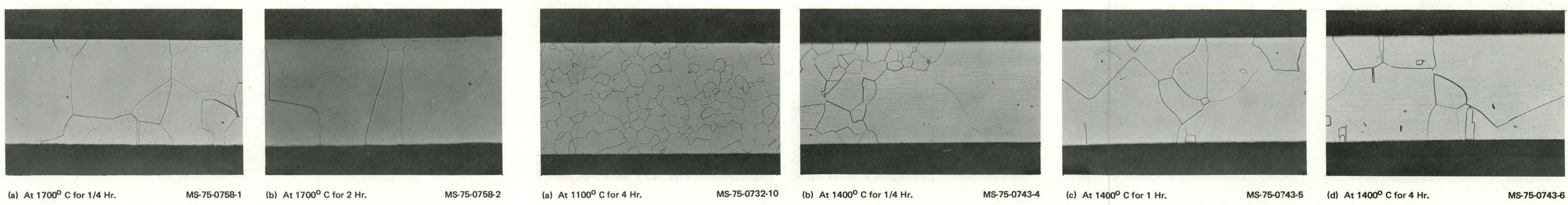

(a) At $1700^{\circ} \mathrm{C}$ for $1 / 4 \mathrm{Hr}$

Ms.75-0758-1 (b) At $1700^{\circ} \mathrm{C}$ for $2 \mathrm{Hr}$

MS-75-07582

(a) At $1100^{\circ} \mathrm{C}$ for $4 \mathrm{Hr}$.

Ms-75-0732-10 (b) At $1400^{\circ} \mathrm{C}$ for $1 / 4 \mathrm{Hr}$.

MS-75-0743-4 (c) At $1400^{\circ} \mathrm{C}$ for $1 \mathrm{Hr}$.

MS-75-0743-5

(a) At $1400^{\circ} \mathrm{C}$ for $4 \mathrm{Hr}$

MS-75-0743-6 

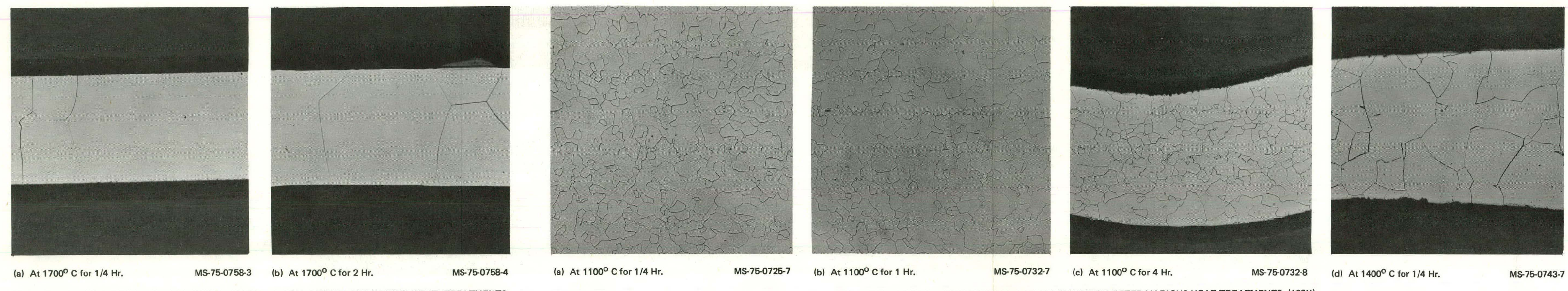
Figure A-5. AS-RECEIVED 7A PLATINUM-8 tUNGSTEN ALLOY RIBBON AFTER TWO HEAT TREATMENTS.
$(100 x)$.

Ms-75-0732-7 (c) At $1100^{\circ} \mathrm{C}$ for $4 \mathrm{H}$

MS 7507328 Figure A-6. AS-WOUND 7A PLATINUM-8 TUNGSTEN ALLOY RIBBON AFTER VARIOUS HEAT TREATMENTS. (100X)
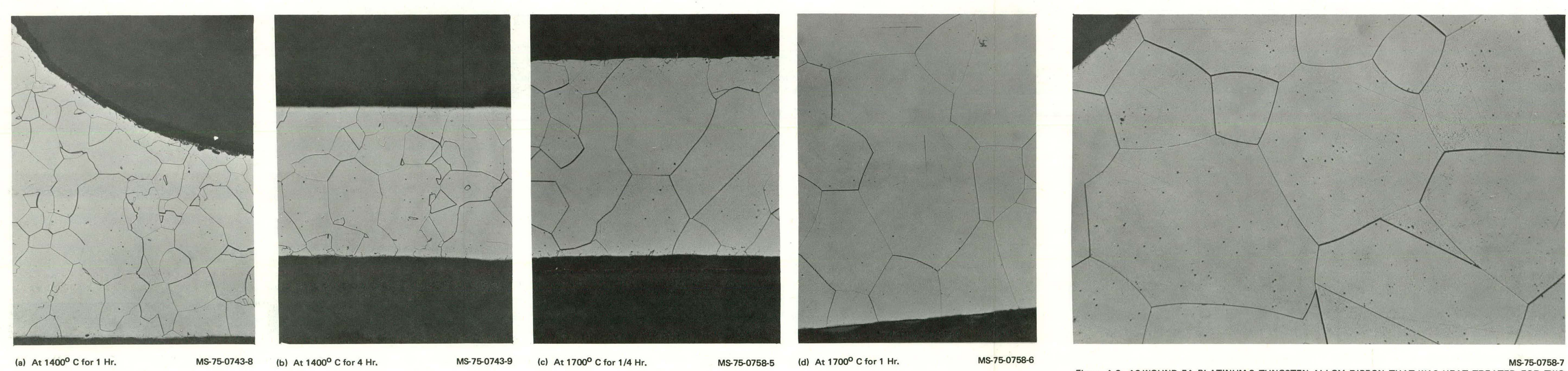

(b) At $1400^{\circ} \mathrm{C}$ for $4 \mathrm{Hr}$

MS-75-0743-9 (c) At $1700^{\circ} \mathrm{C}$ for $1 / 4 \mathrm{Hr}$

MS-75-0758-5 (d) At $1700^{\circ} \mathrm{C}$ for $1 \mathrm{Hr}$

Ms-75-0758-6 Figure A-7. AS.WOUND 7A PLATINUM-8 TUNGSTEN ALLOY RIBBon AFTER VARIOUS HEAT TREATMENTS. (100X)

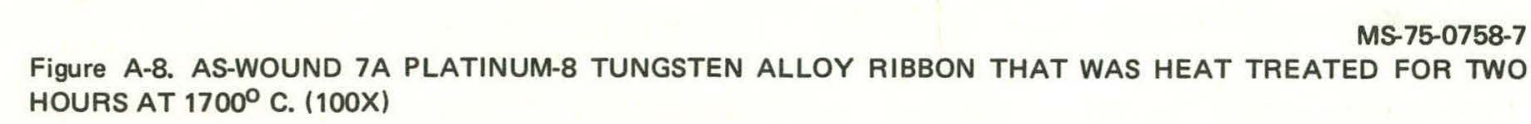




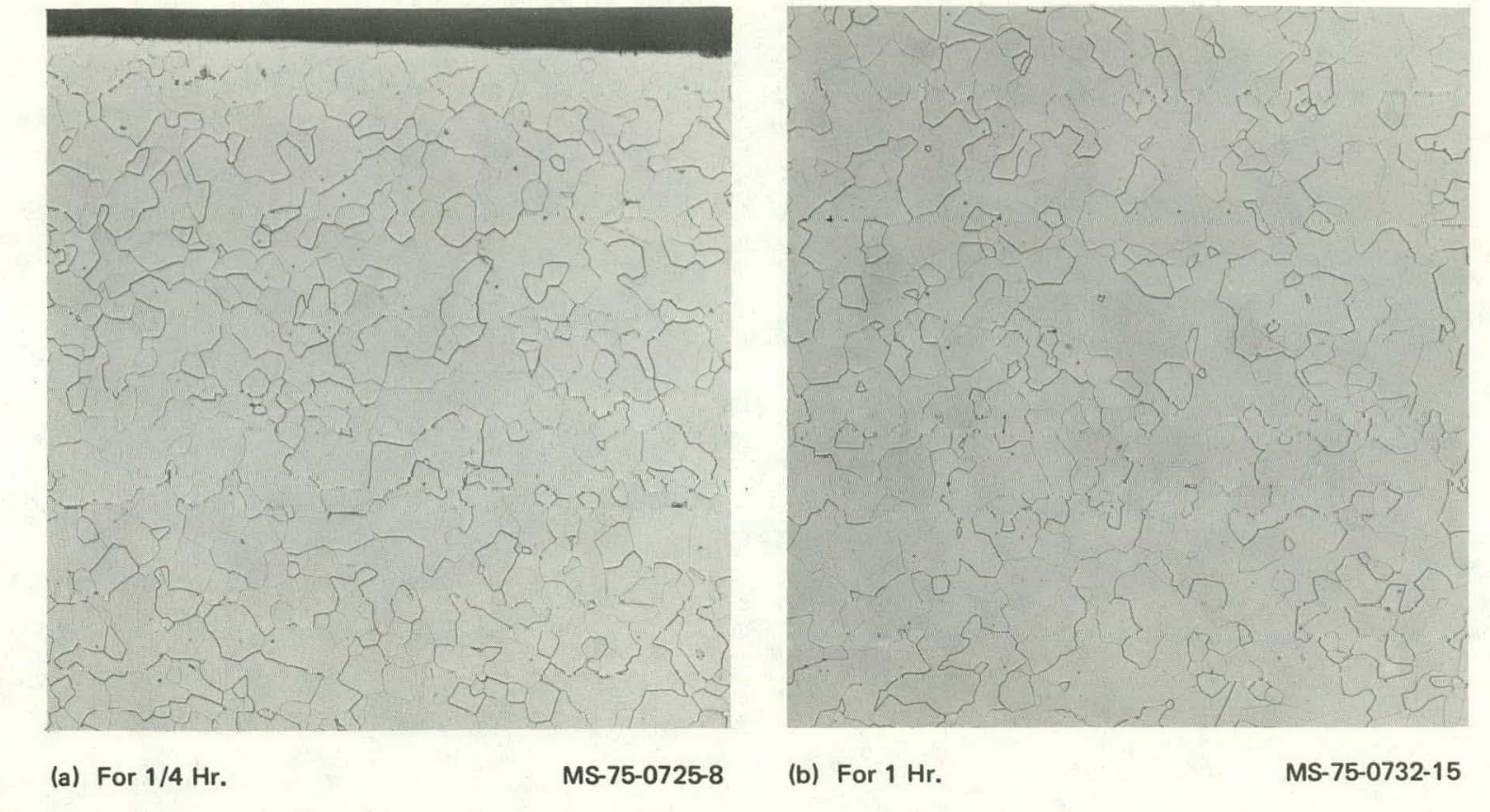

Figure A.9. AS-WOUND AND SWAGED 7A PLATINUMM-8 TUNGSTEN ALLOY RIBBON THAT WAS HEAT TREATED
AT $1100^{\circ}$ C FOR TWO LENGTHS OF TIME (100X)

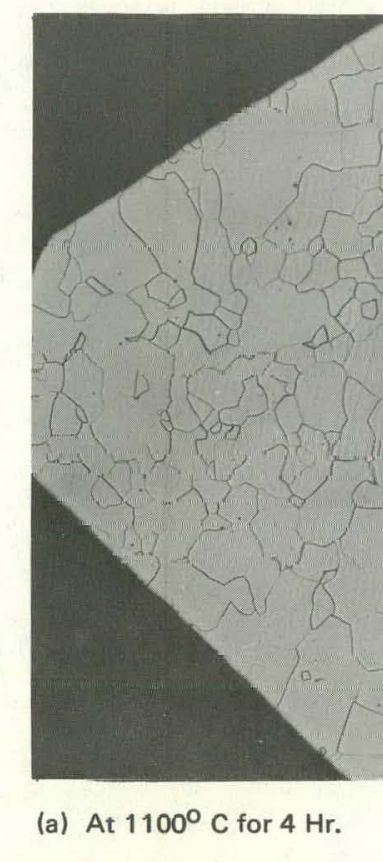

(a) At $1100^{\circ} \mathrm{C}$ for $4 \mathrm{Hr}$.

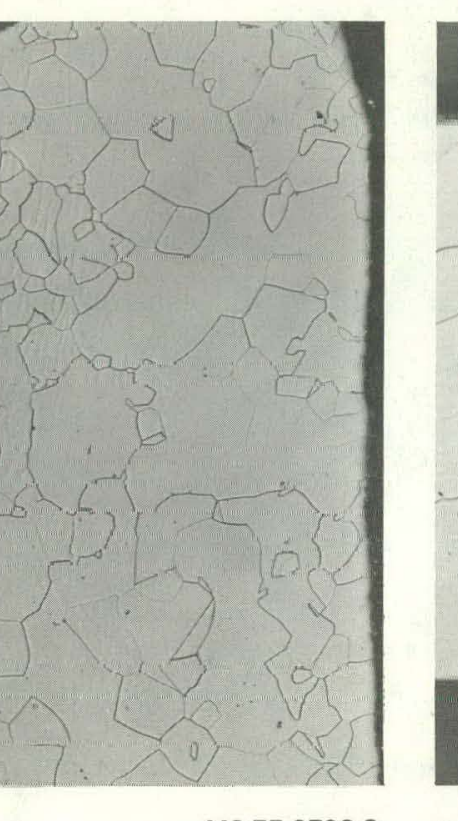
(b) At $1400^{\circ} \mathrm{C}$ for $1 / 4 \mathrm{Hr}$ MS-75-0743-10 (c) At $1400^{\circ} \mathrm{C}$ for $1 \mathrm{Hr}$ MS LLLOY RIBBON AFT

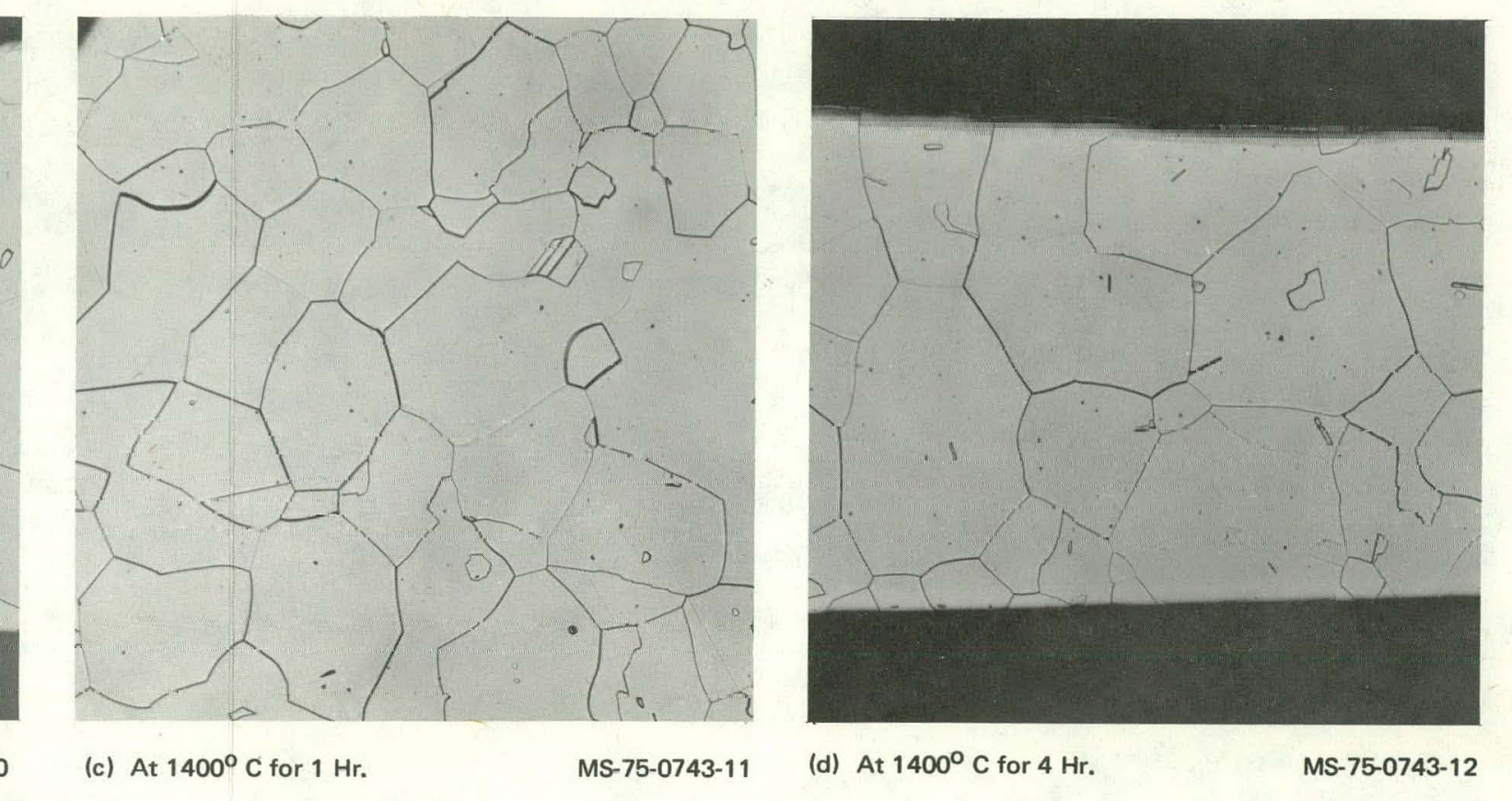

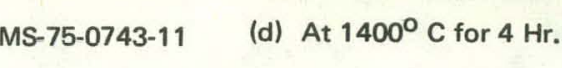
MEAT TREATMENTS. (100X)
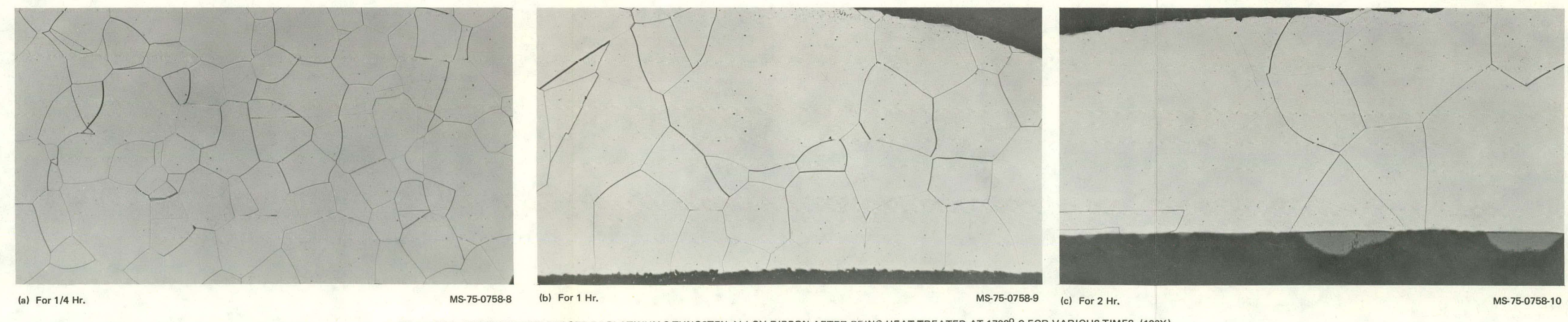

Figure A-11. AS.WOUND AND SWAGED 7A PLATINUM-8 TUNGSTEN ALLOY RIBBon AFTER BEING HEAT TREATED AT $1700^{\circ} \mathrm{C}$ FOR VARIOUS TIMES. (100X) 


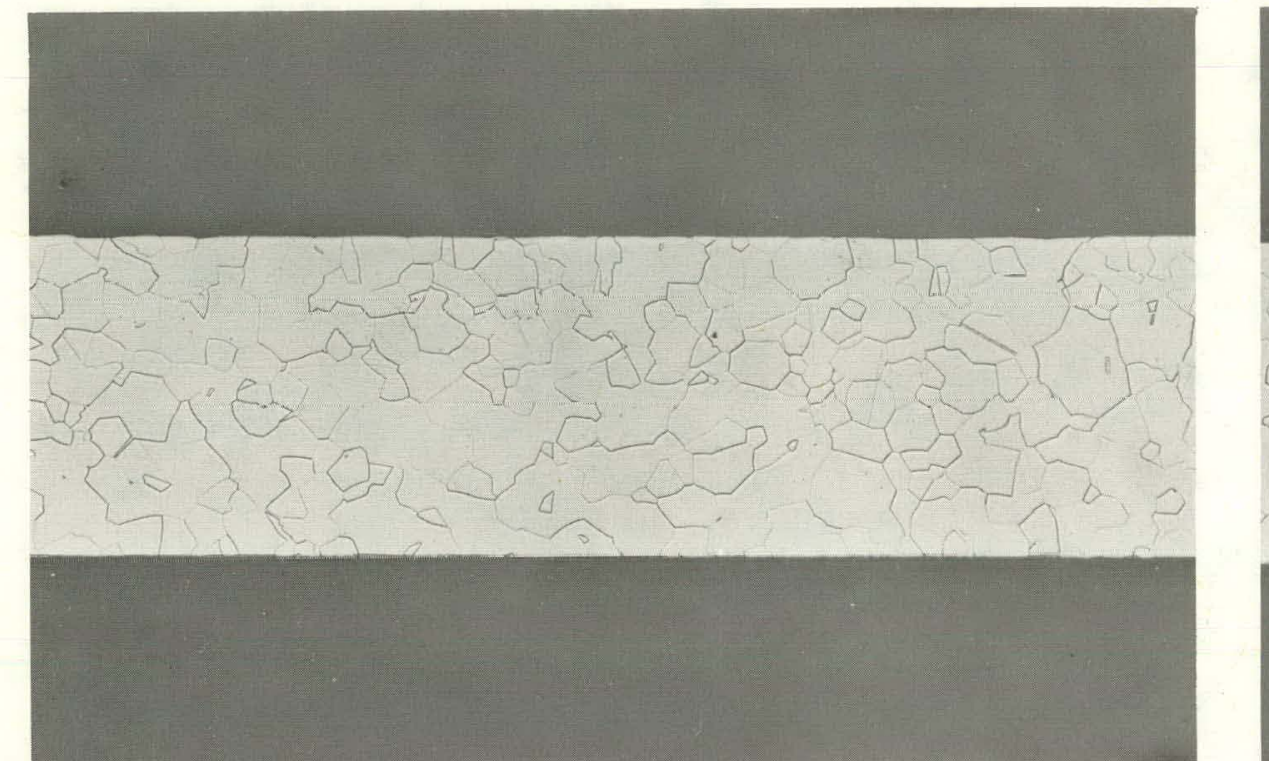

(a) At $800^{\circ} \mathrm{C}$ for $1 / 4 \mathrm{Hr}$.

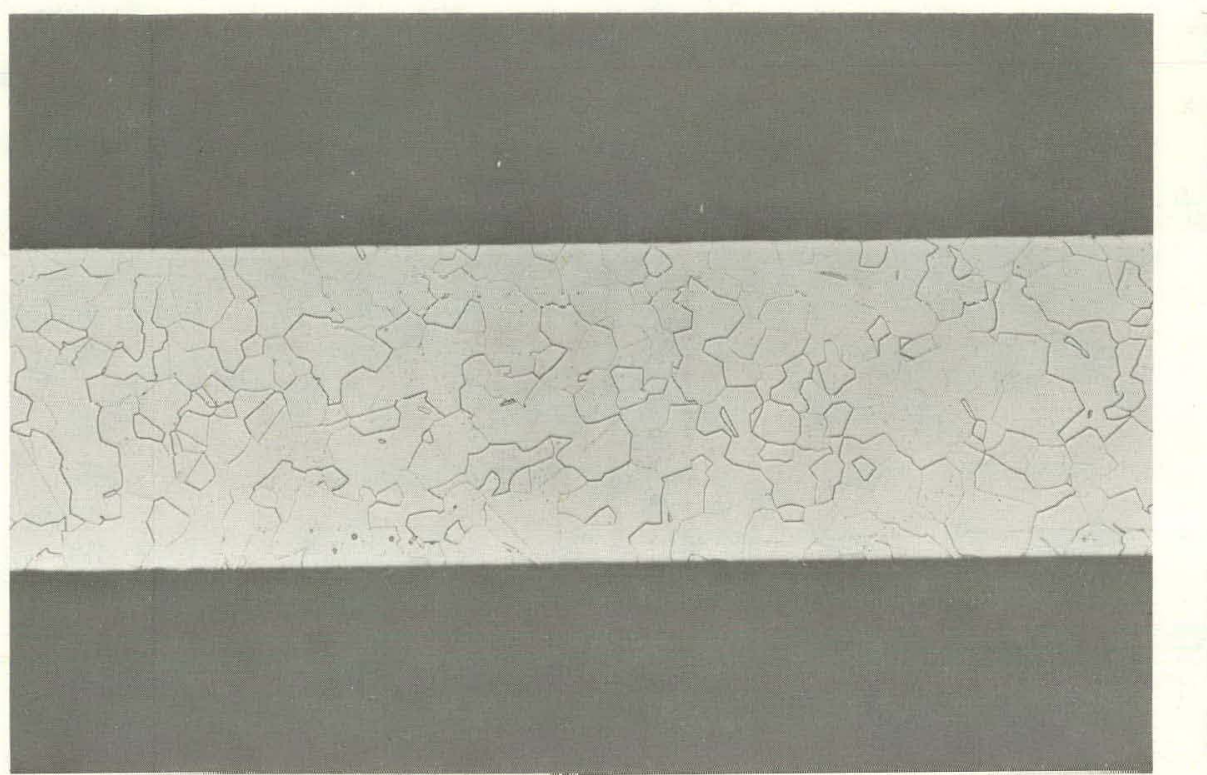

Ms-75-0725-10 (c) At $1100^{\circ} \mathrm{C}$ for $1 / 4 \mathrm{Hr}$

(b) At $800^{\circ} \mathrm{C}$ for $4 \mathrm{Hr}$

Figure A-12. AS-RECEIVED 8A PLATINUM-8 TUNGSTEN ALLOY RIBBON AFTER VARIOUS HEAT TREATMENTS. (100X)
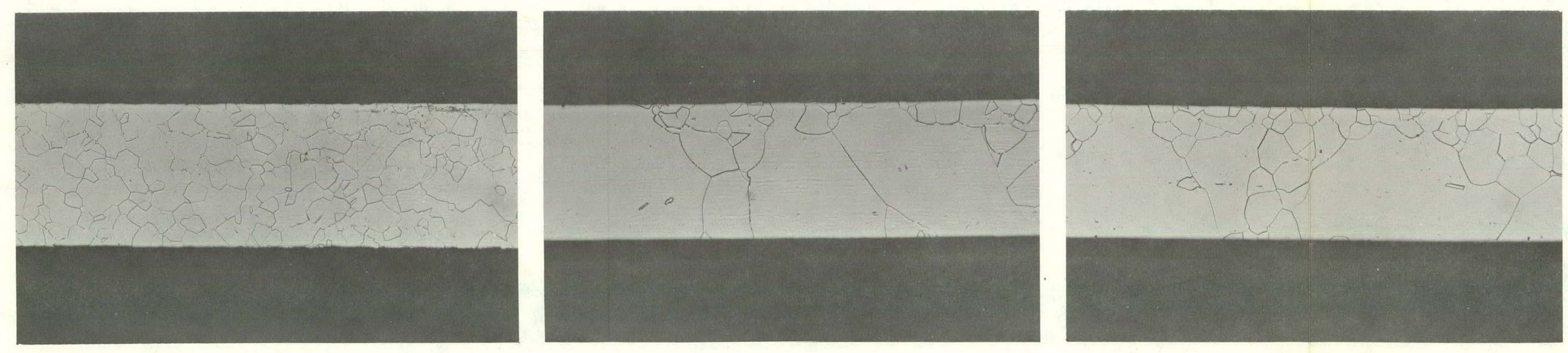

MS-75-0743-13 (c) At $1400^{\circ} \mathrm{C}$ for $1 \mathrm{Hr}$.

Ms.75-0743-14

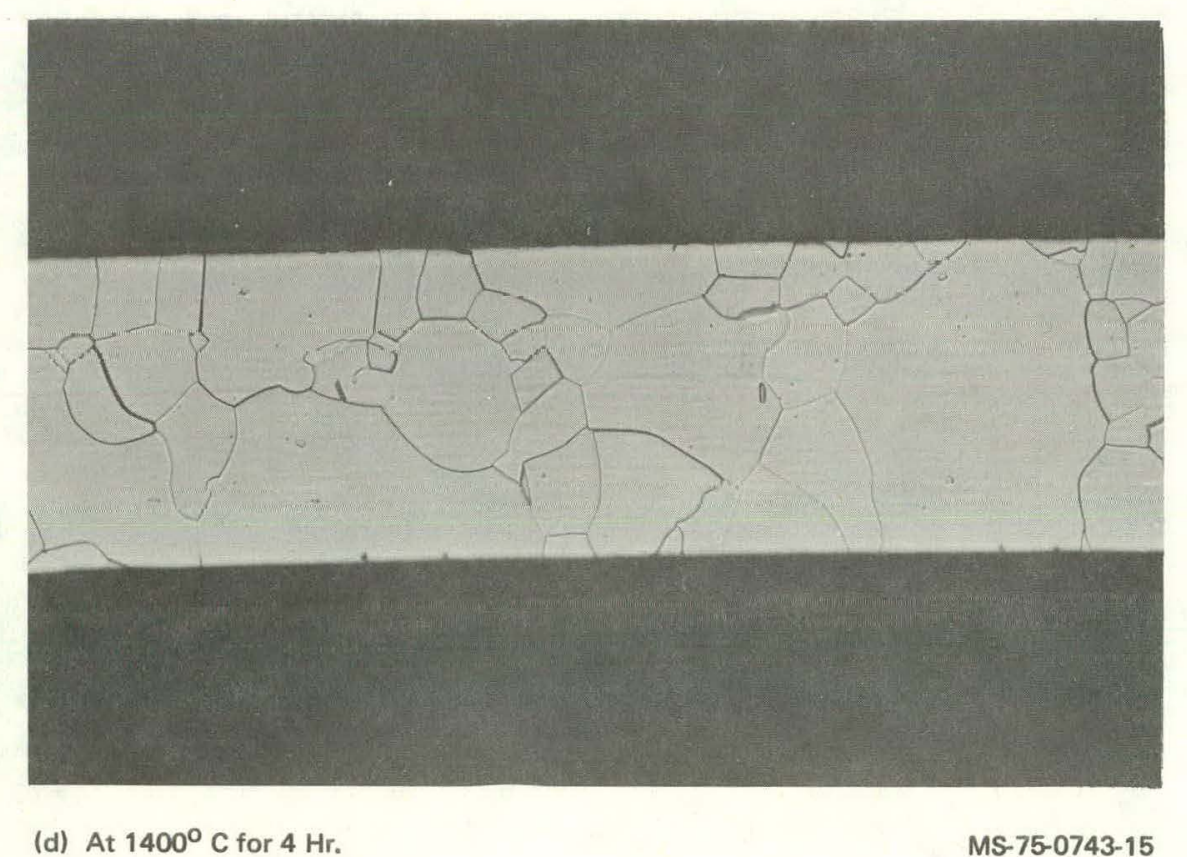




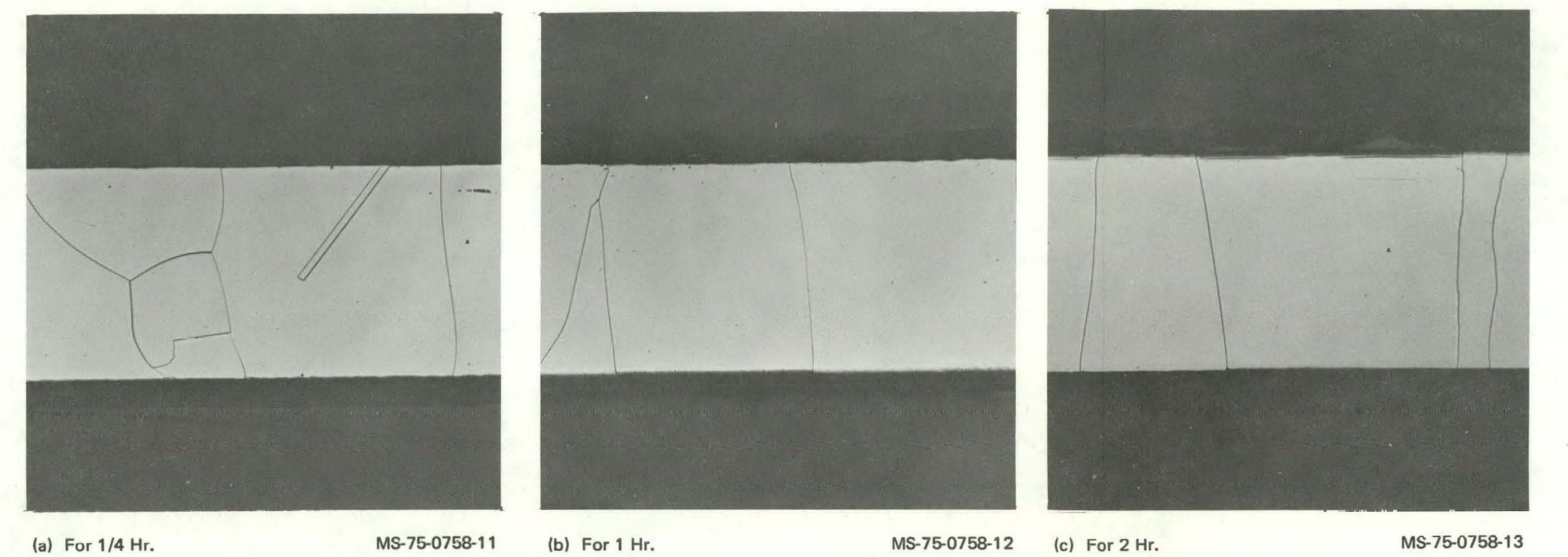

Figure A-14. AS-RECEIVED 8A PLATINUM-8 TUNGSTEN ALLOY RIBBon AFTER VARIOUS HEAT TREATMENTS AT 1700 C. (100X)

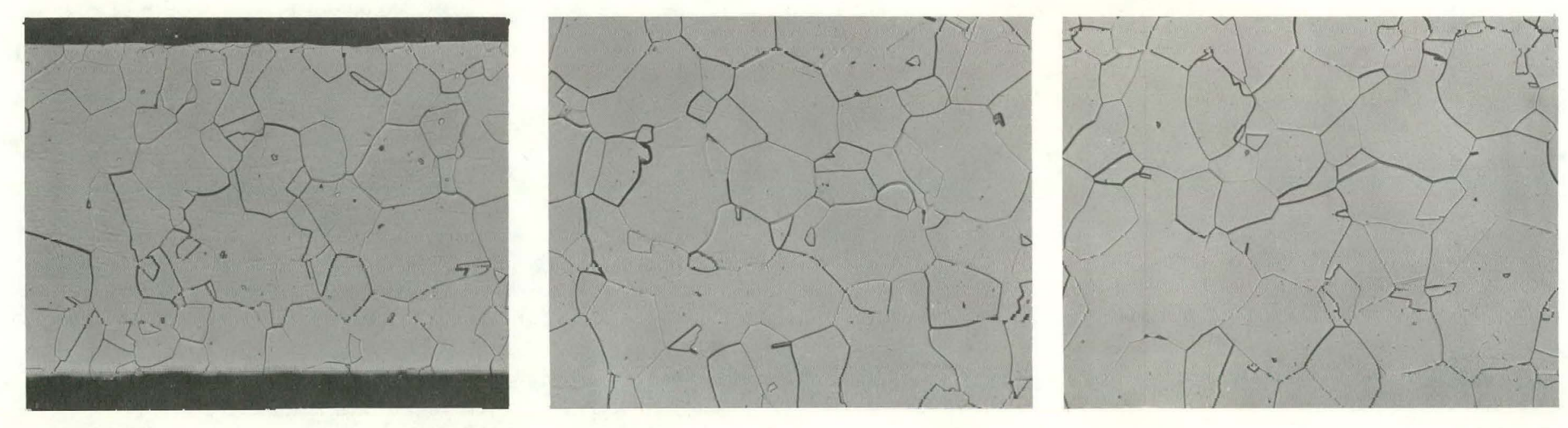

$\begin{array}{llll}\text { MS } 75-0743-16 & \text { (b) For } 1 \mathrm{Hr} . & \text { MS } 75-0743-17 & \text { (c) For } 4 \mathrm{Hr} \text {. }\end{array}$

MS-75-0743-18
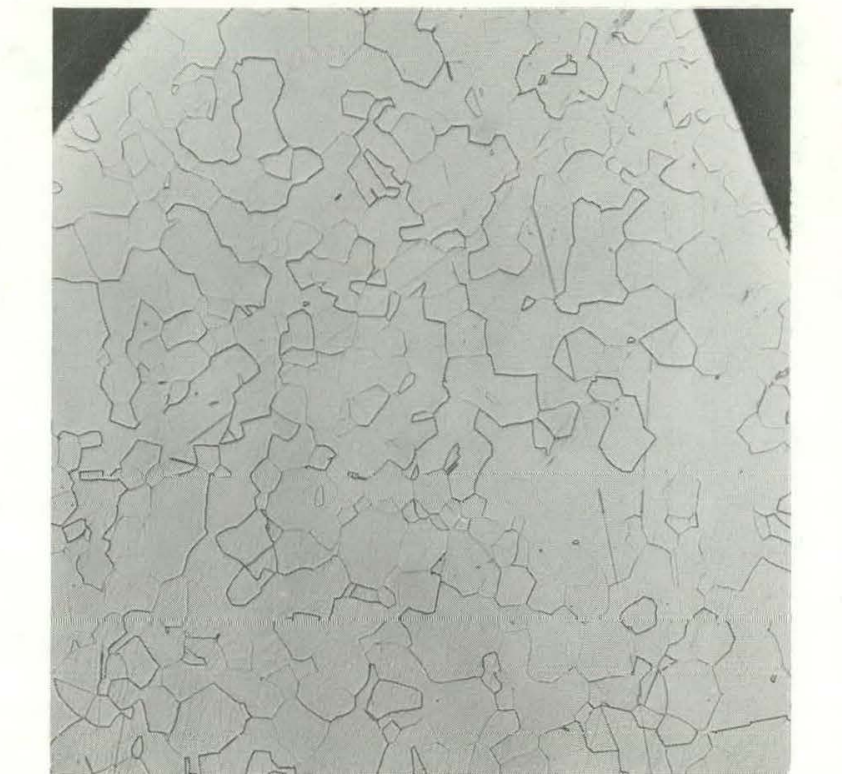

MS-75-0725-12 (b) For $1 \mathrm{Htr}$

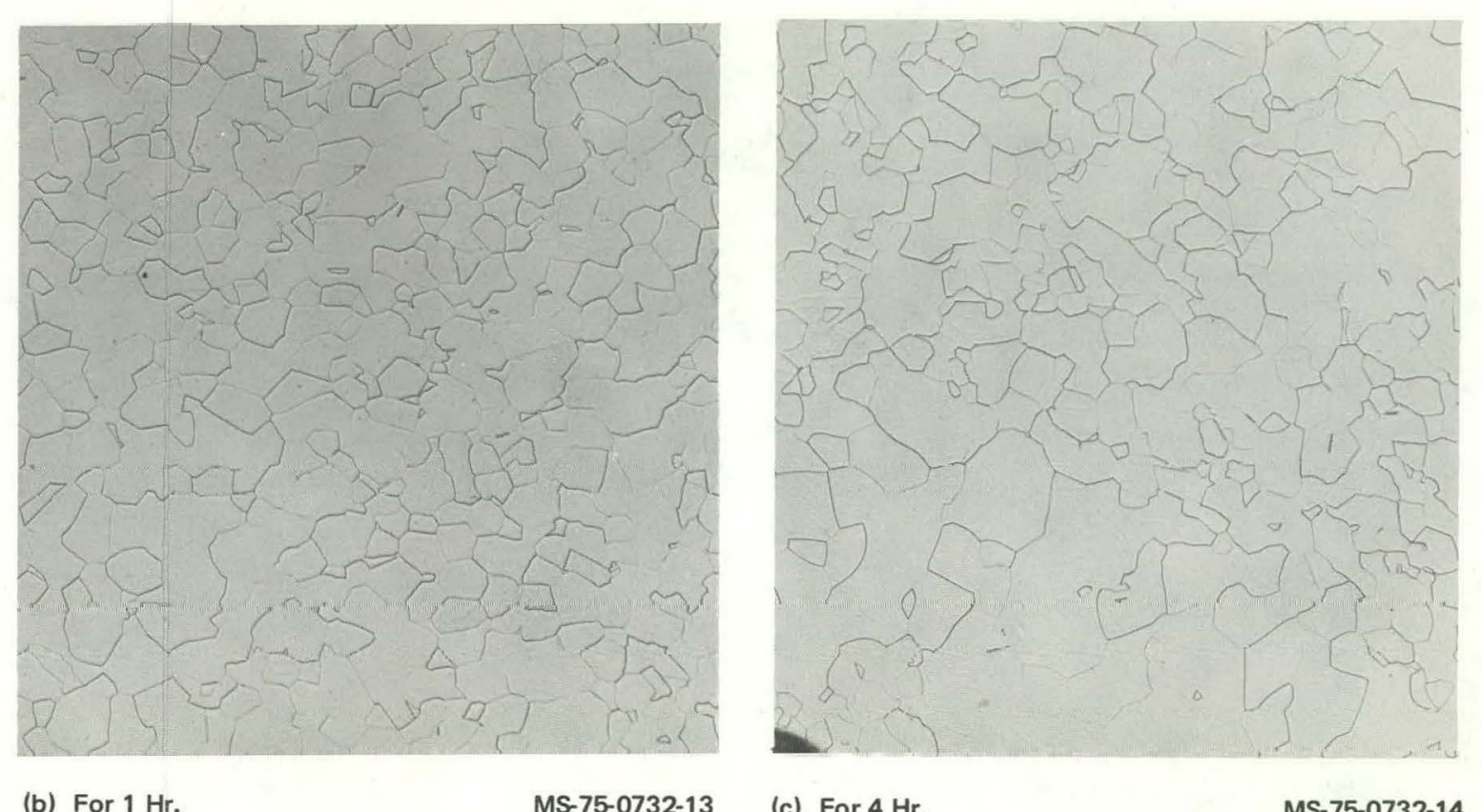

MS-75-0732-13 (c) For $4 \mathrm{Hr}$.

Ms 75-0732-14

Figure A-15. AS-WOUND 8A PLATINUM-8 TUNGSTEN ALLOY RIBBON AFTER VARIOUS HEAT TREATMENTS AT 1100 $\mathrm{C}$. (100X)
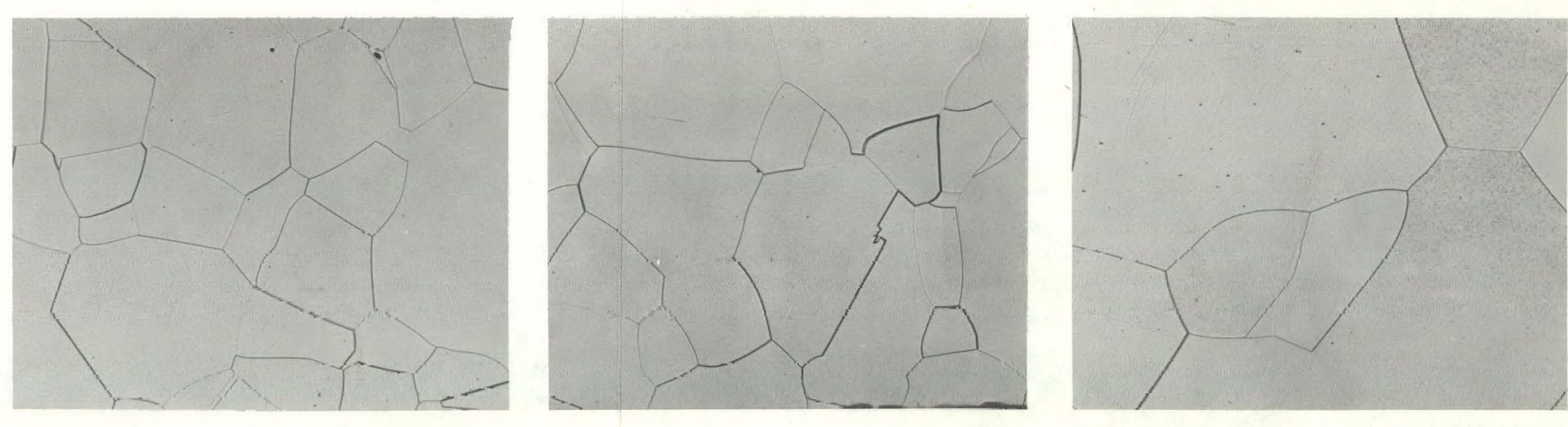

(a) For $1 / 4 \mathrm{Hr}$.

MS-75-0758-14 (b) For 1 Hr.

MS-75-075-15 (c) For $2 \mathrm{Hr}$

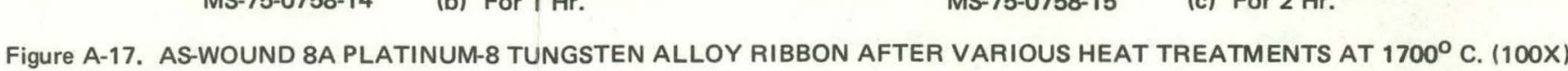

MS-75-0758-16 


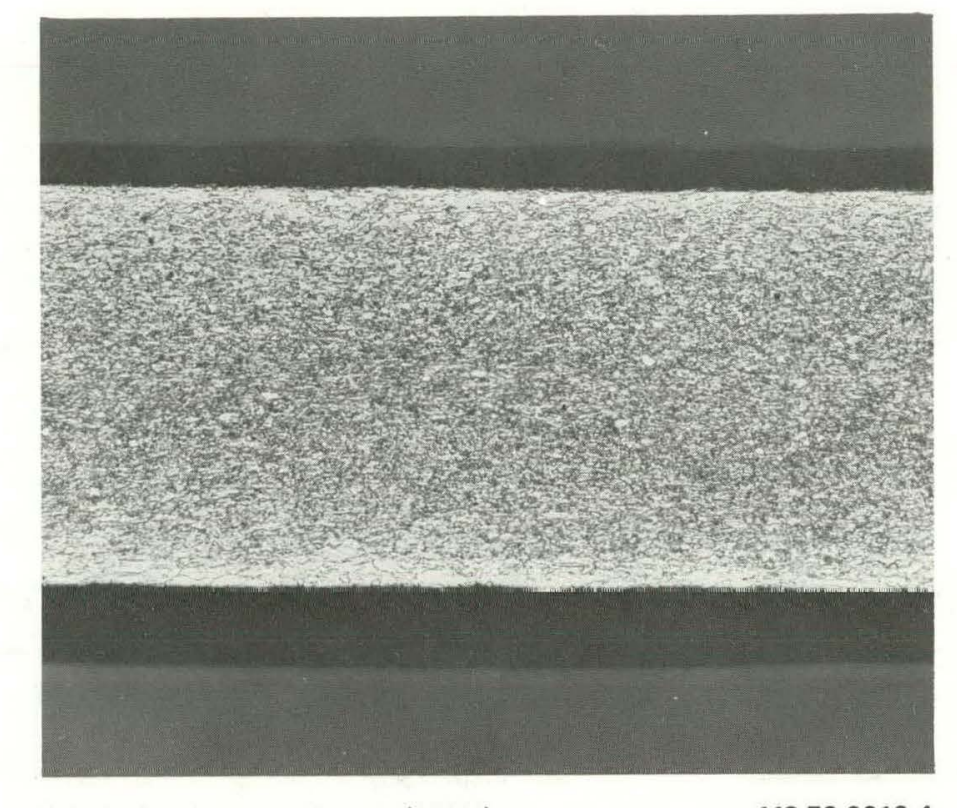

(a) As Cut from the Heater. (100x)

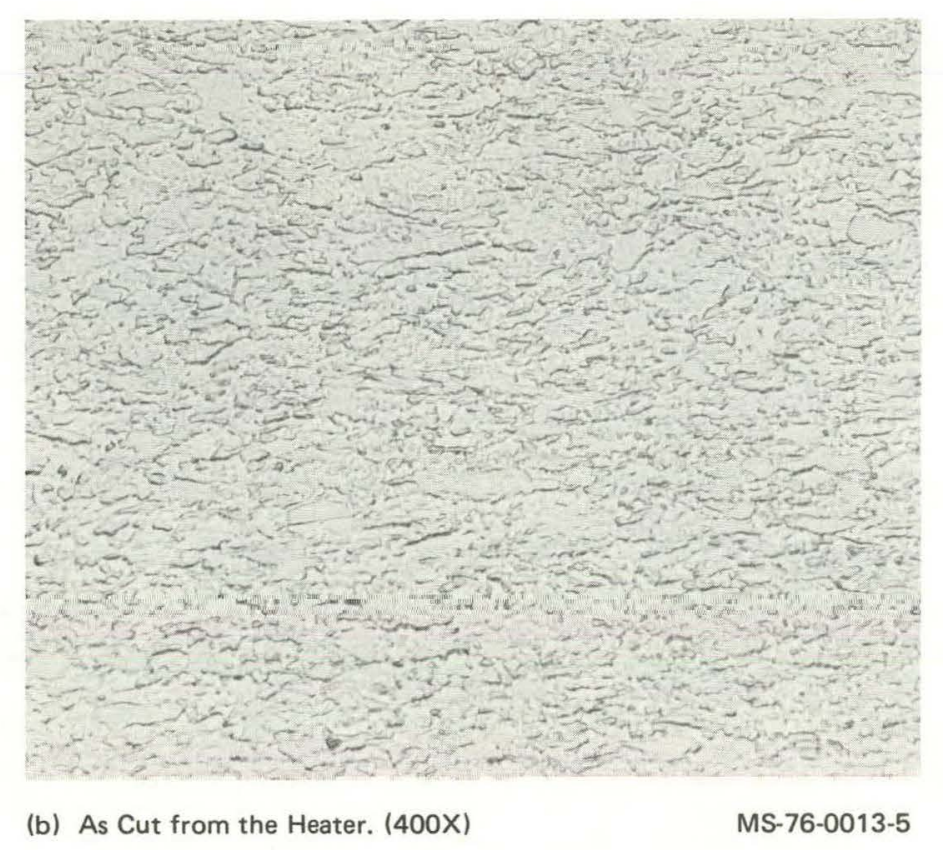

(b) As Cut from the Heater. $(400 x)$

MS $76-0013-5$ (c) Annealed at $1100^{\circ} \mathrm{C}$ for 4 Hr. $100 x$

Figure A-18. SPECIMENS FROM GA HEATER 11 NEAR THE CENTER OF THE WINDING. AAs Cut from the Heater and as Annealed at $1100^{\circ} \mathrm{C}$ for 4 HH

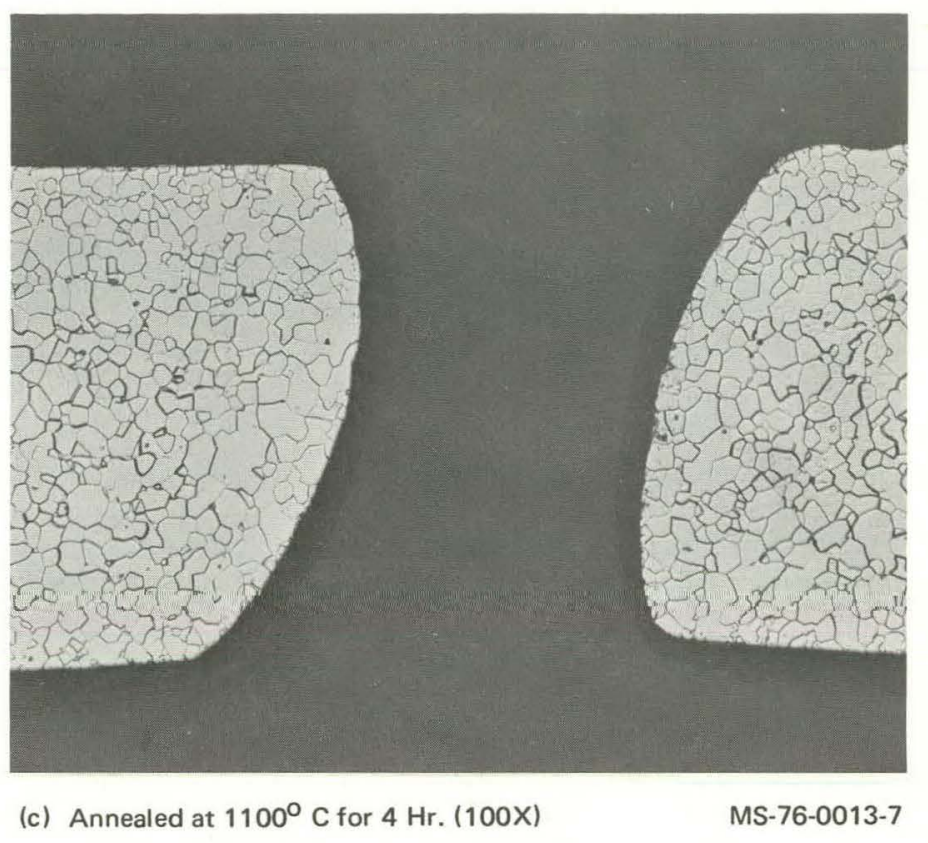

Ms-76-0013-7

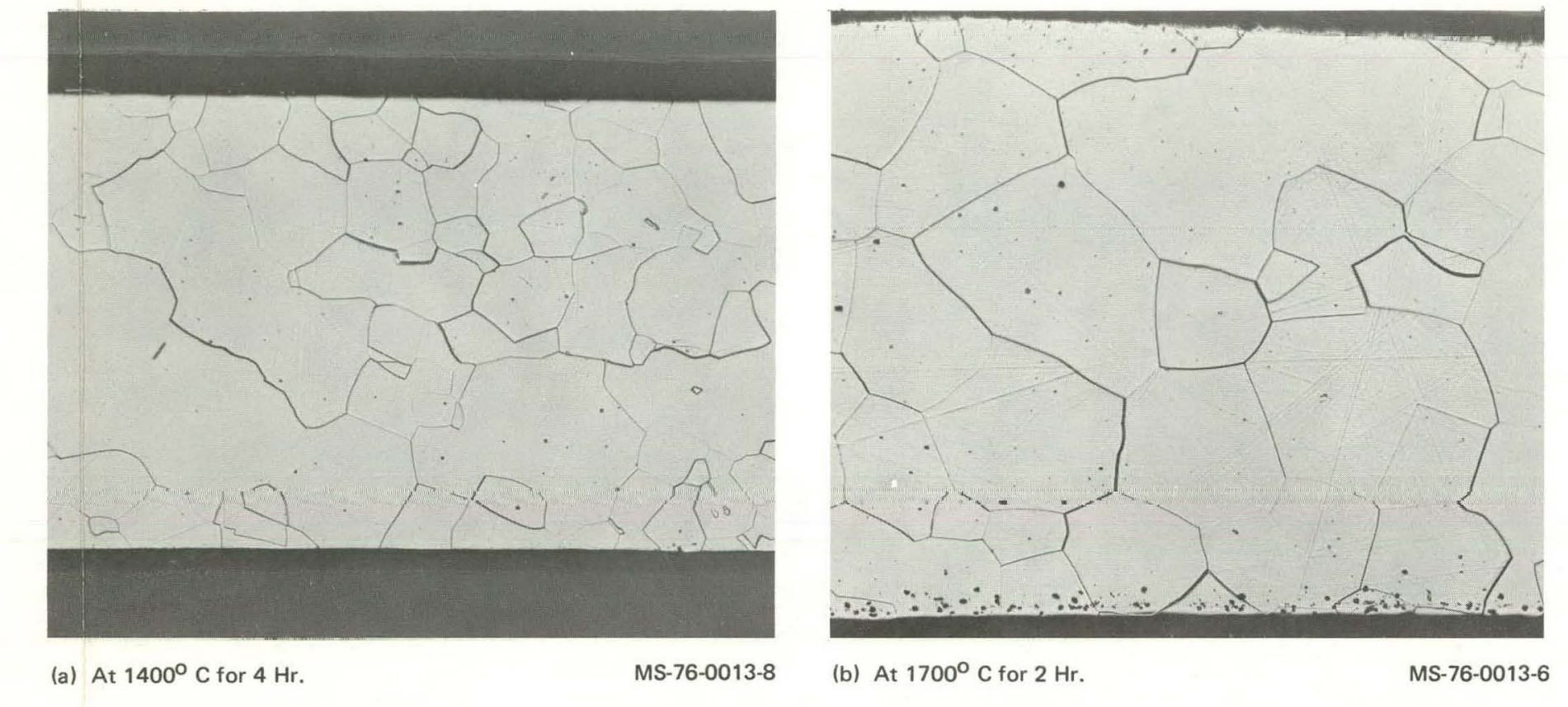

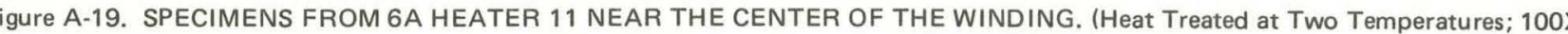

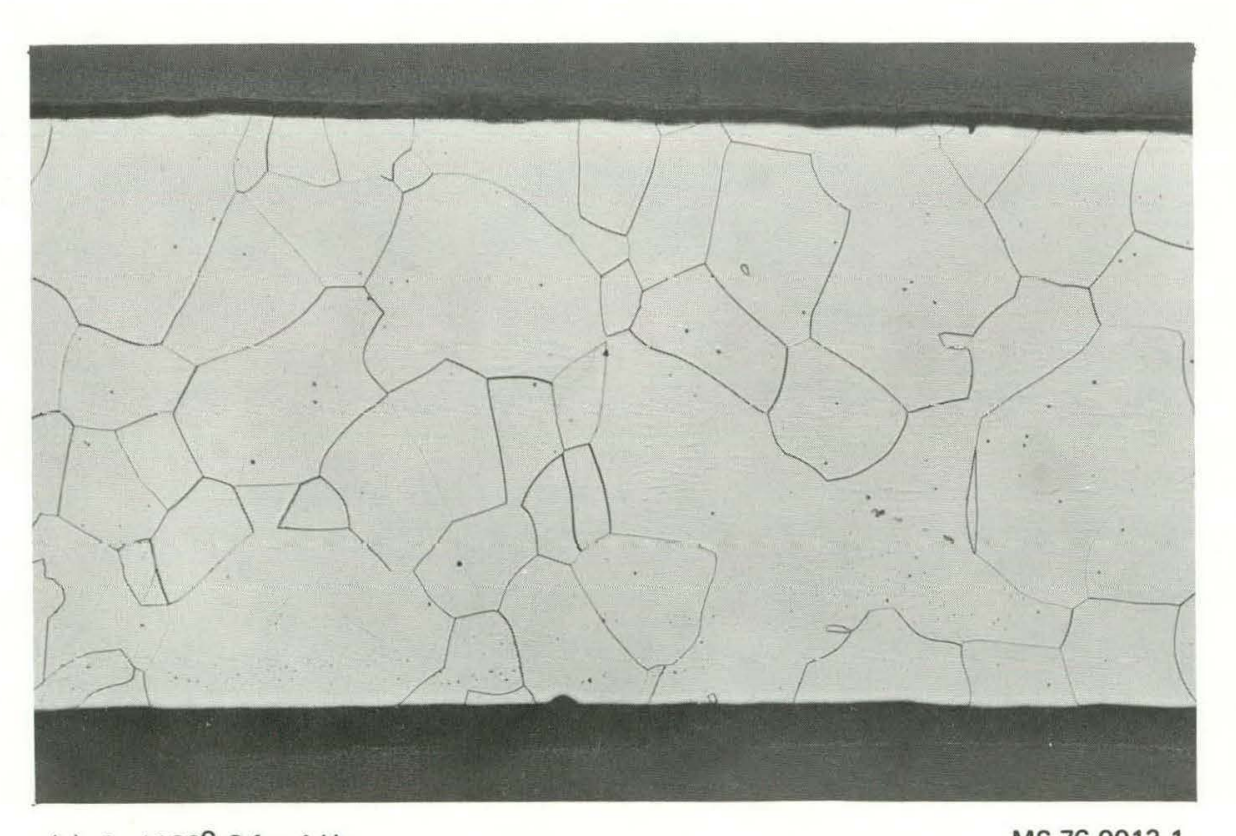

(a) At $1100^{\circ} \mathrm{C}$ for $4 \mathrm{Hr}$

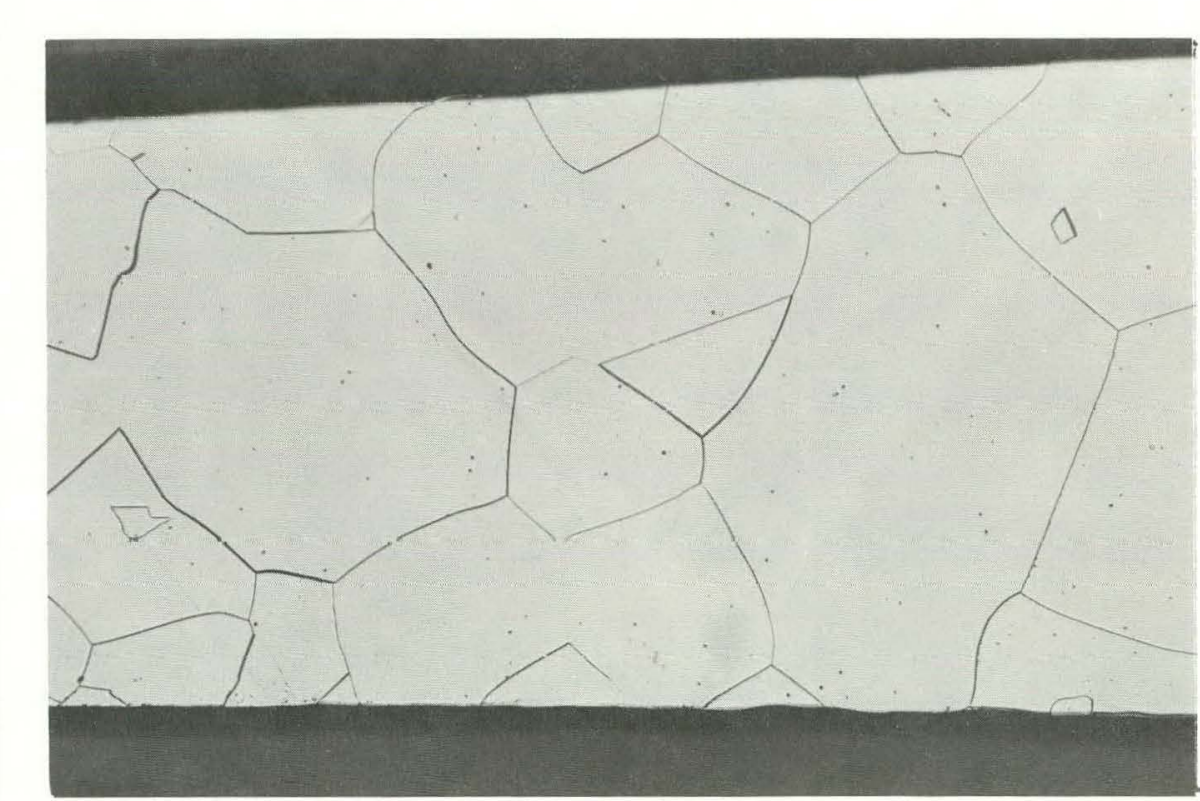

Ms-76-0013-1 (b) At $1400^{\circ} \mathrm{C}$ for $4 \mathrm{Hr}$. Figure A-20. SPECII
Conditions: 100X)

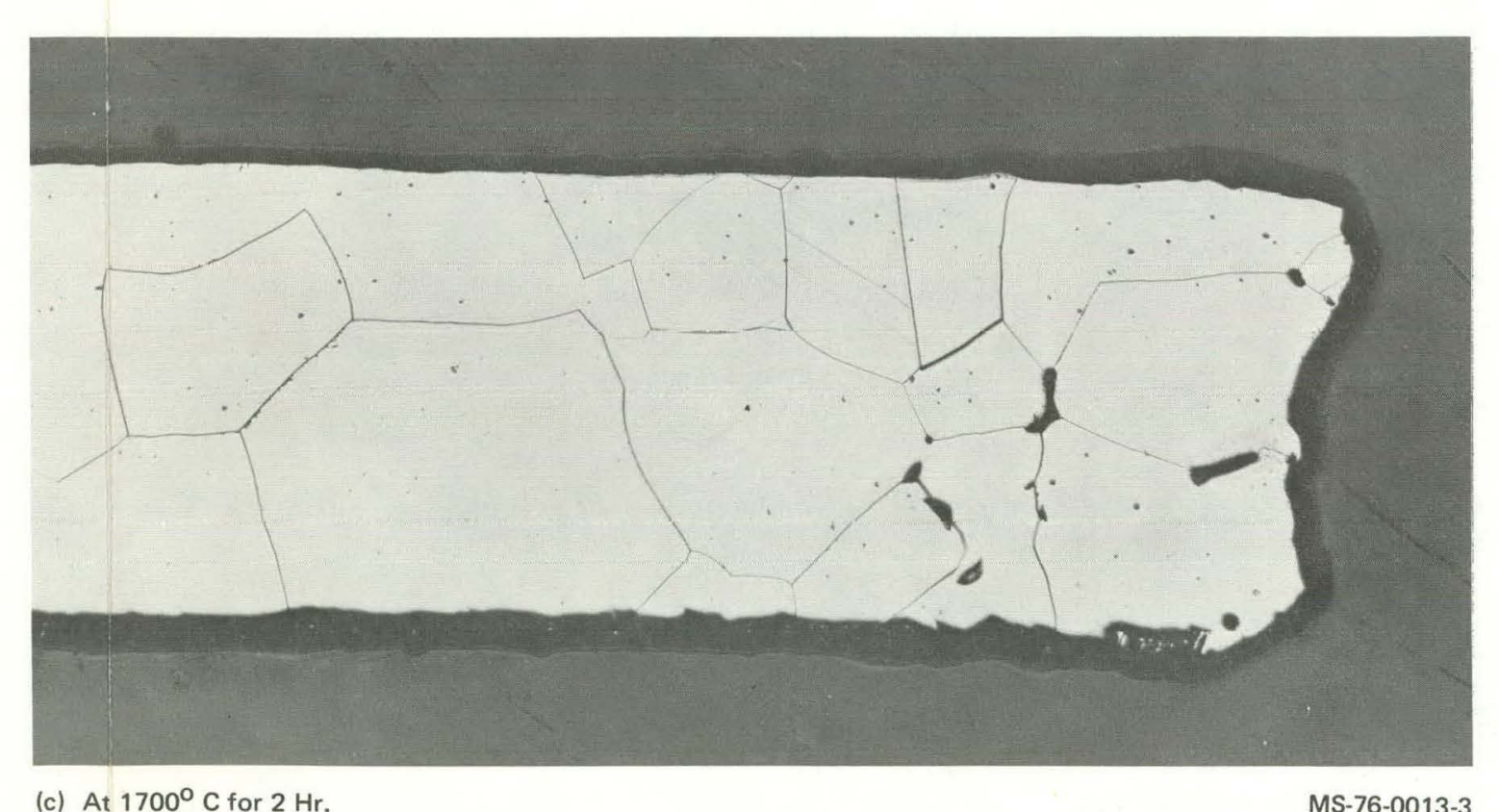

MS-76-0013-2 (c) At $1700^{\circ} \mathrm{C}$ for $2 \mathrm{Hr}$.

GURE 5 . Heat Treated in Vacuum at Various

(1) 


\section{Distribution}

Energy Research and Development Administration - Oak Ridge

Hickman, H. D.

Leed, R. E.

Pidkowicz, J.

Zachry, D. S., Jr

Lawrence Livermore Laboratory

Nelson, W. E.

Los Alamos Scientific Laboratory

Hoyt, H. C.

Oak Ridge Gaseous Diffusion Plant

Stief, S. S.

Wilcox, W. J., Jr

Oak Ridge National Laboratory

Baucum, W. E., Jr

Clark, D. L. (Consultant)

Donnelly, R. G.

Fee, G. G.

Fontana, M. H.

Gat, Uri

Gnadt, P. A.

Grindell, A. G.

Heestand, R. L.

Inouye, $\mathrm{H}$.

MacPherson, R. E., Jr

McCulloch, R. W. (5)

McEIroy, D. L:

Wantland, J. L.

Weir, J. R.

Oak Ridge Y-12 Plant

Alvey, H. E.

Armstrong, R. C.

Bernander, N. K.

Burditt, R. B.

Burkhart, L. E.

Dodson, W. H.

Duggan, $H$. G.

Ebert, T. H.

Ellingson, R. D.

Fraser, R. J. 
Gritzner, V. B.

University of Tennessee - College

Hurst, J. S. of Engineering

Jackson, V. C.

Jones, F. W.

Stansbury, E. E.

Kahl, K. G.

Keith, A.

Kite, H. T.

Koger, J. W. (5)

Ludwig, R. L. (5)

Mills, J. M., Jr

Myhre, T. C.

Phillips, L. R.

Pnst, $\cap \mathrm{W}$

Schreyer, J. M.

Smith, H. F., Jr

Smith, R. D.

Snyder, W. B.,Jr

Stoner, $H$. $H$.

Tewes, W. E.

Tilson, F. V.

Weathersby, W. E.

Yaggi, W. J./Googin, J. M.

$Y-12$ Central Files (master copy)

$Y-12$ Central Files (route copy)

$Y-12$ Central Files $(Y-12 R C)$

$Y$-12 Central Files (5)

Zerby, C. D.

Paducah Gaseous Diffusion Plant

Levin, R. W.

Union Carbide Corporation - New York

Winters, Charles

Union Carbide Corporation - Parma

Research Center

Chambers, W. E.

In addition, this report is distributed in accordance with the categories UC-79e, LMFBR-Reactor Core Systems, and 79p, LMFBR-Safety, as given in the USERDA Standard Distribution Lists for Unclassified Scientific and Technical Reports, TID-4500. 